\title{
Analysis of Heat Transfer in Berman Flow of Nanofluids with Navier Slip, Viscous Dissipation, and Convective Cooling
}

\author{
O. D. Makinde, ${ }^{1}$ S. Khamis, ${ }^{2}$ M. S. Tshehla, ${ }^{1}$ and O. Franks ${ }^{3}$ \\ ${ }^{1}$ Faculty of Military Science, Stellenbosch University, Private Bag Box X2, Saldanha 7395, South Africa \\ ${ }^{2}$ Mathematics and Computational Science and Engineering, Nelson Mandela African Institute of Science and Technology \\ (NM-AIST), Arusha, Tanzania \\ ${ }^{3}$ Faculty of Engineering Built Environment and Information Technology, Nelson Mandela Metropolitan University, \\ P.O. Box 77000, Port Elizabeth 6031, South Africa \\ Correspondence should be addressed to O. D. Makinde; makinded@gmail.com
}

Received 10 February 2014; Accepted 26 February 2014; Published 31 March 2014

Academic Editor: R. N. Jana

Copyright (C) 2014 O. D. Makinde et al. This is an open access article distributed under the Creative Commons Attribution License, which permits unrestricted use, distribution, and reproduction in any medium, provided the original work is properly cited.

\begin{abstract}
Heat transfer characteristics of a Berman flow of water based nanofluids containing copper $(\mathrm{Cu})$ and alumina $\left(\mathrm{Al}_{2} \mathrm{O}_{3}\right)$ as nanoparticles in a porous channel with Navier slip, viscous dissipation, and convective cooling are investigated. It is assumed that the exchange of heat with the ambient surrounding takes place at the channel walls following Newton's law of cooling. The governing partial differential equations and boundary conditions are converted into a set of nonlinear ordinary differential equations using appropriate similarity transformations. These equations are solved analytically by regular perturbation methods with series improvement technique and numerically using an efficient Runge-Kutta Fehlberg integration technique coupled with shooting scheme. The effects of the governing parameters on the dimensionless velocity, temperature, skin friction, pressure drop, and Nusselt numbers are presented graphically and discussed quantitatively.
\end{abstract}

\section{Introduction}

The study of fluid flow and heat transfer between two porous boundaries has gained tremendous attention of researchers due to its wide applications in engineering and industrial processes. Some of the practical interests include problems dealing with transpiration cooling where the walls of a channel containing heated fluid are protected from overheating by passing cooler fluid over the exterior surface of the channel; fluid flow occurring during the separation of isotopes of Uranium-235 and Uranium-238 by gaseous diffusion in order to produce fuel for nuclear reactors; controlling boundary layer flow over aircraft wings by injection or suction of fluid out of or into the wing; lubrication of porous bearings; petroleum technology; ground water hydrology; seepage of water in river beds; purification and filtration processes; methods of decreasing rates of heat transfer in combustion chambers exhaust nozzles and porous walled flow reactors, and so forth. In a pioneering work, Berman [1] presented an exact solution of the Navier-Stokes equations that describes the steady two-dimensional flow of an incompressible viscous fluid along a channel with parallel rigid porous walls, under the action of uniform suction or injection of fluid at the surface. Sellars [2] extended Berman's work to high suction Reynolds number. Yuan [3] considered the flow in a channel with porous walls. He obtained solutions for small suction and injection values and asymptotic solution valid at large injection values. Terrill $[4,5]$ gave an exact series solution for the fully developed laminar flow in a pipe of circular cross section with porous wall driven by a spatially variable and time independent suction or injection at the surface. Studies on developing flow in porous-walled ducts with suction and injection effects were carried out by Sorour et al. [6] and Zaturska et al. [7]. In view of the above interests, several researchers have also investigated the heat transfer problems between two permeable parallel walls under different physical situations [8-10].

Moreover, the applications of conventional heat transfer fluids such as water and glycol mixture in engineering flow 
processes are limited due to their low thermal properties. A potential solution to improve these thermal properties is to add nanoparticles into the conventional fluids, hence forming the so-called nanofluids as coined by Choi [11]. Nanofluids contain thermally conducting submicron solid particles and have great potential as a high-energy carrier. The nanoparticles such as copper, alumina, titania, and copper oxide, unlike larger-sized particles, can be suspended stably within the conventional fluids without settling out of suspension. Nanofluids are free from numerous problems such as abrasion, clogging, and high pressure loss and are considered to be the next-generation working fluids in modern heat transfer technologies [12]. Experimental results [1315] have shown that, even with small solid volume fraction of nanoparticles (usually less than 5\%), the thermal conductivity of heat transfer fluids can be enhanced by $10-50 \%$. Several authors [16-18] have also theoretically investigated the heat transfer enhancement of nanofluids under different physical conditions.

Meanwhile, advances in the manufacture of microdevices have enabled experimental investigation of fluid flow in nano- and microscale, and many experimental results have provided evidences to support the slip condition $[19,20]$. In order to describe the slip characteristics of fluid on the solid surface, Navier [21] introduced a more general boundary condition, namely, the fluid velocity component tangential to the solid surface, relative to the solid surface, which is proportional to the shear stress on the fluid-solid interface. The proportionality is called the slip length which describes the slipperiness of the surface. However, from the literature survey, it is found that no study has been conducted on the heat transfer characteristics of Berman flow of nanofluids with Navier slip, viscous dissipation, or convective cooling at the walls. Hence, the present study is an attempt in this direction. The flow of water base nanofluids containing copper $(\mathrm{Cu})$ and alumina $\left(\mathrm{Al}_{2} \mathrm{O}_{3}\right)$ as nanoparticles in a uniformly porous wall channel with Navier slip, viscous dissipation, and convective heat exchange with the ambient surrounding is investigated. Sections $2-4$ give in more details the model nonlinear governing equations together with the analytical and numerical solution techniques employed to tackle the problem. In Section 5, we present graphically and discuss the main features of the flow and heat transfer characteristics in a range of governing parameters. Final conclusions are drawn in Section 6. To the best of our knowledge, the results of this paper are new and they have not been published before.

\section{Problem Formulation}

Consider a two-dimensional steady flow of a viscous incompressible water base nanofluids containing copper $(\mathrm{Cu})$ and alumina $\left(\mathrm{Al}_{2} \mathrm{O}_{3}\right)$ as nanoparticles in a uniformly porous wall channel. The channel wall is subjected to Navier slip and convectively exchange heat with the ambient surrounding. We choose the Cartesian coordinates system in such a way that the $x$-axis is taken along the channel and the $y$-axis is normal to it as shown in Figure 1.

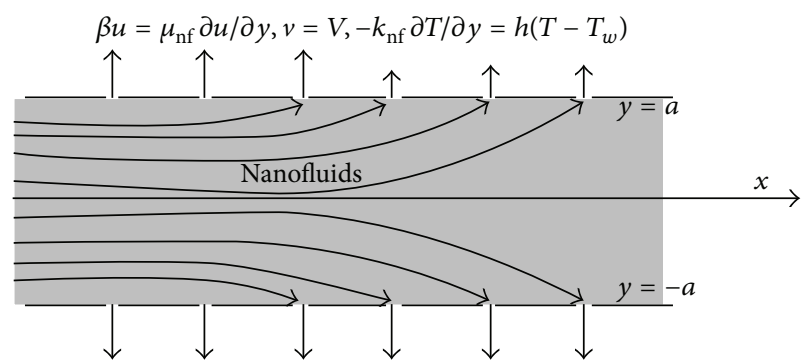

FIGURE 1: Schematic diagram of the physical system.

The governing equations which are those of conservation of mass, momentum, and energy are $[1-5,8-10]$

$$
\begin{gathered}
\frac{\partial u}{\partial x}+\frac{\partial v}{\partial y}=0 \\
\rho_{\mathrm{nf}}\left(u \frac{\partial u}{\partial x}+v \frac{\partial u}{\partial y}\right)=-\frac{\partial p}{\partial x}+\mu_{\mathrm{nf}}\left(\frac{\partial^{2} u}{\partial y^{2}}+\frac{\partial^{2} u}{\partial x^{2}}\right), \\
\rho_{\mathrm{nf}}\left(u \frac{\partial v}{\partial x}+v \frac{\partial v}{\partial y}\right)=-\frac{\partial p}{\partial y}+\mu_{\mathrm{nf}}\left(\frac{\partial^{2} v}{\partial y^{2}}+\frac{\partial^{2} v}{\partial x^{2}}\right), \\
u \frac{\partial T}{\partial x}+v \frac{\partial T}{\partial y}=\frac{k_{\mathrm{nf}}}{\left(\rho c_{p}\right)_{\mathrm{nf}}}\left(\frac{\partial^{2} T}{\partial x^{2}}+\frac{\partial^{2} T}{\partial y^{2}}\right) \\
+\frac{2 \mu_{\mathrm{nf}}}{\left(\rho c_{p}\right)_{\mathrm{nf}}}\left[\left(\frac{\partial u}{\partial x}\right)^{2}+\left(\frac{\partial v}{\partial y}\right)^{2}\right] \\
+\frac{\mu_{\mathrm{nf}}}{\left(\rho c_{p}\right)_{\mathrm{nf}}}\left(\frac{\partial v}{\partial x}+\frac{\partial u}{\partial y}\right)^{2}
\end{gathered}
$$

where $(u, v)$ are the velocity components of the nanofluid in the $(x, y)$ directions, respectively, $V(>0)$ uniform wall suction velocity, $P$ is the pressure, $T$ is the nanofluid temperature, $\mu_{\mathrm{nf}}$ is the effective dynamic viscosity of the nanofluid [22], $k_{\mathrm{nf}}$ is the effective thermal conductivity of the nanofluid [23], and $\rho_{\mathrm{nf}}$ and $\left(\rho c_{p}\right)_{\mathrm{nf}}$ are the nanofluid density and the heat capacitance of the nanofluid, respectively, which are given by [13-18].

$$
\begin{gathered}
\mu_{\mathrm{nf}}=\frac{\mu_{f}}{(1-\varphi)^{2.5}}, \quad \rho_{\mathrm{nf}}=(1-\varphi) \rho_{f}+\varphi \rho_{s} \\
\alpha_{\mathrm{nf}}=\frac{k_{\mathrm{nf}}}{\left(\rho c_{p}\right)_{\mathrm{nf}}} \\
\frac{k_{\mathrm{nf}}}{k_{f}}=\frac{\left(k_{s}+2 k_{f}\right)-2 \varphi\left(k_{f}-k_{s}\right)}{\left(k_{s}+2 k_{f}\right)+\varphi\left(k_{f}-k_{s}\right)} \\
\left(\rho c_{p}\right)_{\mathrm{nf}}=(1-\varphi)\left(\rho c_{p}\right)_{f}+\varphi\left(\rho c_{p}\right)_{s}
\end{gathered}
$$

where $\varphi$ is the nanoparticles solid volume fraction, $\rho_{f}$ is the reference density of the fluid fraction, $\rho_{s}$ is the reference density of the solid fraction, $\mu_{f}$ is the viscosity of the fluid fraction, $k_{f}$ is the thermal conductivity of the fluid fraction, $c_{p}$ 
is the specific heat at constant pressure, and $k_{s}$ is the thermal conductivity of the solid volume fraction.

Due to the symmetric nature of the flow, the boundary conditions at the channel centerline and at the porous wall may be written as [1-4]

$$
\begin{gathered}
\frac{\partial u}{\partial y}(x, 0)=0, \quad \frac{\partial T}{\partial y}(x, 0)=0, \quad v(x, 0)=0, \\
\beta u(x, a)=\mu_{\mathrm{nf}} \frac{\partial u}{\partial y}(x, a), \quad v(x, a)=V, \\
-k_{\mathrm{nf}} \frac{\partial T}{\partial y} T(x, a)=h\left[T(x, a)-T_{w}\right],
\end{gathered}
$$

where $T_{w}$ is the ambient surrounding temperature, $h$ is the coefficient of heat transfer, and $\beta$ is the Navier slip coefficient. Introduce the stream function $\psi$ and vorticity $\Omega$ into the governing equations (1)-(4) as follows:

$$
u=\frac{\partial \psi}{\partial y}, \quad v=-\frac{\partial \psi}{\partial x}, \quad \Omega=\frac{\partial u}{\partial y}-\frac{\partial v}{\partial x}=\frac{\partial^{2} \psi}{\partial y^{2}}+\frac{\partial^{2} \psi}{\partial x^{2}}
$$
obtain

After eliminating the pressure $P$ from (2) and (3), we

$$
\begin{aligned}
& \rho_{\mathrm{nf}}\left(\frac{\partial \psi}{\partial y} \frac{\partial \Omega}{\partial x}-\frac{\partial \psi}{\partial x} \frac{\partial \Omega}{\partial y}\right)=\mu_{\mathrm{nf}}\left(\frac{\partial^{2} \Omega}{\partial y^{2}}+\frac{\partial^{2} \Omega}{\partial x^{2}}\right) \\
&\left(\frac{\partial \psi}{\partial y} \frac{\partial T}{\partial x}-\frac{\partial \psi}{\partial x} \frac{\partial T}{\partial y}\right)= \frac{k_{\mathrm{nf}}}{\left(\rho c_{p}\right)_{\mathrm{nf}}}\left(\frac{\partial^{2} T}{\partial y^{2}}+\frac{\partial^{2} T}{\partial x^{2}}\right) \\
&+\frac{4 \mu_{\mathrm{nf}}}{\left(\rho c_{p}\right)_{\mathrm{nf}}}\left(\frac{\partial^{2} \psi}{\partial x \partial y}\right)^{2} \\
&+\frac{\mu_{\mathrm{nf}}}{\left(\rho c_{p}\right)_{\mathrm{nf}}}\left(-\frac{\partial^{2} \psi}{\partial x^{2}}+\frac{\partial^{2} \psi}{\partial y^{2}}\right)^{2}
\end{aligned}
$$

The following dimensionless variables and parameters are introduced into (8), together with their corresponding boundary conditions:

$$
\begin{gathered}
\eta=\frac{y}{a}, \quad \bar{\psi}=\frac{\psi}{V a}, \quad \bar{\Omega}=\frac{\Omega a}{V}, \quad \Phi=\frac{T-T_{w}}{T_{w}}, \\
R=\frac{V a}{v_{f}}, \quad X=\frac{x}{a}, \quad v_{f}=\frac{\mu_{f}}{\rho_{f}}, \\
\operatorname{Pr}=\frac{\mu_{f} c_{p}}{k_{f}}, \quad m_{1}=\left(1-\varphi+\frac{\varphi \rho_{s}}{\rho_{f}}\right)(1-\varphi)^{2.5},
\end{gathered}
$$

$$
\begin{gathered}
\lambda=\frac{\mu_{f}}{\beta a}, \quad \bar{P}=\frac{a P}{V \mu_{f}}, \\
m_{2}=m_{4}\left(1-\varphi+\frac{\varphi\left(\rho c_{p}\right)_{s}}{\left(\rho c_{p}\right)_{f}}\right), \quad \mathrm{Bi}=\frac{h a}{k_{f}}, \\
\mathrm{Ec}=\frac{V^{2}}{c_{p} T_{w}}, \\
m_{3}=\frac{m_{4}}{(1-\varphi)^{2.5}}, \quad m_{4}=\frac{\left(k_{s}+2 k_{f}\right)+\varphi\left(k_{f}-k_{s}\right)}{\left(k_{s}+2 k_{f}\right)-2 \varphi\left(k_{f}-k_{s}\right)},
\end{gathered}
$$

and we obtain

$$
\begin{aligned}
m_{1} R\left(\frac{\partial \bar{\psi}}{\partial \eta} \frac{\partial \bar{\Omega}}{\partial X}-\frac{\partial \bar{\psi}}{\partial X} \frac{\partial \bar{\Omega}}{\partial \eta}\right) & =\left(\frac{\partial^{2} \bar{\Omega}}{\partial \eta^{2}}+\frac{\partial^{2} \bar{\Omega}}{\partial X^{2}}\right) \\
m_{2} R \operatorname{Pr}\left(\frac{\partial \bar{\psi}}{\partial \eta} \frac{\partial \Phi}{\partial X}-\frac{\partial \bar{\psi}}{\partial X} \frac{\partial \Phi}{\partial \eta}\right)= & \left(\frac{\partial^{2} \Phi}{\partial \eta^{2}}+\frac{\partial^{2} \Phi}{\partial X^{2}}\right) \\
& +4 m_{3} \operatorname{Ec} \operatorname{Pr}\left(\frac{\partial^{2} \bar{\psi}}{\partial X \partial \eta}\right)^{2} \\
& +m_{3} \operatorname{Ec} \operatorname{Pr}\left(-\frac{\partial^{2} \bar{\psi}}{\partial X^{2}}+\frac{\partial^{2} \bar{\psi}}{\partial \eta^{2}}\right)^{2}
\end{aligned}
$$

with

$$
\begin{gathered}
\frac{\partial^{2} \bar{\psi}}{\partial \eta^{2}}(X, 0)=0, \quad \frac{\partial \Phi}{\partial \eta}(X, 0)=0, \quad \frac{\partial \bar{\psi}}{\partial X}(X, 0)=0, \\
\frac{\partial \bar{\psi}}{\partial \eta}(X, 1)=\frac{\lambda \quad \frac{\partial^{2} \bar{\psi}}{(1-\varphi)^{2.5}}(X, 1), \quad \frac{\partial \bar{\psi}}{\partial \eta^{2}}(x, a)=-1,}{\frac{\partial \Phi}{\partial \eta}(X, 1)=-m_{4} \operatorname{Bi} \Phi(X, 1),}
\end{gathered}
$$

where $R$ is the flow Reynolds number such that $R>0$ represents wall suction and $R<0$ represents wall injection; $\mathrm{Ec}$ is the Eckert number; $\mathrm{Bi}$ is the Biot number; $\mathrm{Pr}$ is the base fluid Prandtl number; $m_{1}, m_{2}, m_{3}$, and $m_{4}$ can be easily determined from the thermophysical properties of the base fluid and the nanoparticles; and $\lambda$ is the Navier slip parameter such that $\lambda=0$ corresponds to no slip, while full lubrication is described in the limit $\lambda \rightarrow \infty$. We seek a similarity form of solution due to Berman [1]; that is,

$$
\begin{gathered}
\bar{\psi}(X, \eta)=X F(\eta), \quad W(X, \eta)=X \frac{d F}{d \eta} \\
\Phi(X, \eta)=H(\eta)+X^{2} \theta(\eta) .
\end{gathered}
$$


Equations (10)-(11) together with the boundary conditions in (12) then become

$$
\begin{gathered}
\frac{d^{4} F}{d \eta^{4}}=m_{1} R\left(\frac{d F}{d \eta} \frac{d^{2} F}{d \eta^{2}}-F \frac{d^{3} F}{d \eta^{3}}\right) \\
\frac{d^{2} \theta}{d \eta^{2}}=-m_{3} \operatorname{Ec} \operatorname{Pr}\left(\frac{d^{2} F}{d \eta^{2}}\right)^{2}+m_{2} R \operatorname{Pr}\left(2 \theta \frac{d F}{d \eta}-F \frac{d \theta}{d \eta}\right) \\
\frac{d^{2} H}{d \eta^{2}}=-2 \theta-4 m_{3} \operatorname{Ec} \operatorname{Pr}\left(\frac{d F}{d \eta}\right)^{2}-m_{2} R \operatorname{Pr} F \frac{d H}{d \eta} \\
\frac{d^{2} F}{d \eta^{2}}(0)=0, \quad \frac{d \theta}{d \eta}(0)=0, \quad \frac{d H}{d \eta}(0)=0, \quad F(0)=0 \\
\frac{d F}{d \eta}(1)=b \frac{d^{2} F}{d \eta^{2}}(1), \quad F(1)=-1 \\
\frac{d \theta}{d \eta}(1)=-m_{4} \operatorname{Bi} \theta(1), \quad \frac{d H}{d \eta}(1)=-m_{4} \operatorname{Bi} H(1)
\end{gathered}
$$

where $b=\lambda /(1-\varphi)^{2.5}$. The dimensionless fluid axial pressure gradient is given as follows:

$$
-\frac{\partial \bar{P}}{\partial X}=X A
$$

where

$$
(1-\varphi)^{2.5} A=-\frac{d^{3} F}{d \eta^{3}}+m_{1} R\left[\left(\frac{d F}{d \eta}\right)^{2}-F \frac{d^{2} F}{d \eta^{2}}\right] .
$$

Other quantities of practical interest in this study are the local skin friction coefficient $C_{f}$ and the local Nusselt number $\mathrm{Nu}$, which are defined as

$$
C_{f}=\frac{a \tau_{w}}{\mu_{f} V}, \quad \mathrm{Nu}=\frac{a q_{w}}{k_{f} T_{w}},
$$

where $\tau_{w}$ is the skin friction and $q_{w}$ is the heat flux at the channel walls which are given by

$$
\tau_{w}=\left.\mu_{\mathrm{nf}} \frac{\partial u}{\partial y}\right|_{y=a}, \quad q_{w}=-\left.k_{\mathrm{nf}} \frac{\partial T}{\partial y}\right|_{y=a} .
$$

Using (2) and (13), we substitute (22) into (21) and obtain

$$
\begin{gathered}
C_{f}=\frac{X}{(1-\varphi)^{2.5}} \frac{d^{2} F}{d \eta^{2}}(1), \\
\mathrm{Nu}=-\frac{k_{\mathrm{nf}}}{k_{f}}\left[\frac{d H}{d \eta}(1)+X^{2} \frac{d \theta}{d \eta}(1)\right] .
\end{gathered}
$$

In the following section, the boundary value problem (14)-(18) was solved analytically using regular perturbation method and numerically by the Runge-Kutta-Fehlberg method with shooting technique [24]. The results are utilised to compute the fluid pressure gradient, local skin friction, and local Nusselt number as highlighted in (20) and (23).

\section{Perturbation Method}

Due to the nonlinear nature of the model equations (14)(18), it is convenient to form a power series expansion in the parameter $R$; that is,

$$
F(\eta)=\sum_{i=0}^{\infty} F_{i} R^{i}, \quad \theta(\eta)=\sum_{i=0}^{\infty} \theta_{i} R^{i}
$$

Substituting the solution series in (24) into (14)-(18) and collecting the coefficients of like powers of $R$, we obtain the following.

\section{Zeroth Order. Consider}

$$
\begin{gathered}
\frac{d^{4} F_{0}}{d \eta^{4}}=0, \quad \frac{d^{2} \theta_{0}}{d \eta^{2}}=-m_{3} \operatorname{Ec} \operatorname{Pr}\left(\frac{d^{2} F_{0}}{d \eta^{2}}\right)^{2}, \\
\frac{d^{2} H_{0}}{d \eta^{2}}=-2 \theta_{0}-4 m_{3} \operatorname{Ec} \operatorname{Pr}\left(\frac{d F_{0}}{d \eta}\right)^{2},
\end{gathered}
$$

with

$$
\begin{gathered}
\frac{d^{2} F_{0}}{d \eta^{2}}(0)=0, \quad \frac{d \theta_{0}}{d \eta}(0)=0, \\
\frac{d H_{0}}{d \eta}(0)=0, \quad F_{0}(0)=0, \\
\frac{d F_{0}}{d \eta}(1)=b \frac{d^{2} F_{0}}{d \eta^{2}}(1), \quad F_{0}(1)=-1, \\
\frac{d \theta_{0}}{d \eta}(1)=-m_{4} \operatorname{Bi} \theta_{0}(1), \quad \frac{d H_{0}}{d \eta}(1)=-m_{4} B i H_{0}(1) .
\end{gathered}
$$

Higher Order $(n \geq 1)$. Consider

$$
\begin{aligned}
\frac{d^{4} F_{n}}{d \eta^{4}}= & m_{1} R \sum_{i=0}^{n-1}\left(\frac{d F_{i}}{d \eta} \frac{d^{2} F_{n-i-1}}{d \eta^{2}}-F_{i} \frac{d^{3} F_{n-i-1}}{d \eta^{3}}\right), \\
\frac{d^{2} \theta_{n}}{d \eta^{2}}= & -m_{3} \operatorname{Ec} \operatorname{Pr} \sum_{i=0}^{n}\left(\frac{d^{2} F_{i}}{d \eta^{2}} \frac{d^{2} F_{n-i}}{d \eta^{2}}\right) \\
& +m_{2} \operatorname{RPr} \sum_{i=0}^{n-1}\left(2 \theta_{i} \frac{d F_{n-i-1}}{d \eta}-F_{i} \frac{d \theta_{n-i-1}}{d \eta}\right), \\
\frac{d^{2} H_{n}}{d \eta^{2}}= & -2 \theta_{n}-4 m_{3} \operatorname{Ec} \operatorname{Pr} \sum_{i=0}^{n}\left(\frac{d F_{i}}{d \eta} \frac{d F_{n-i}}{d \eta}\right) \\
& -m_{2} R \operatorname{Pr} \sum_{i=0}^{n-1}\left(F_{i} \frac{d H_{n-i-1}}{d \eta}\right),
\end{aligned}
$$


with

$$
\begin{gathered}
\frac{d^{2} F_{n}}{d \eta^{2}}(0)=0, \quad \frac{d \theta_{n}}{d \eta}(0)=0, \\
\frac{d H_{n}}{d \eta}(0)=0, \quad F_{n}(0)=0, \\
\frac{d F_{n}}{d \eta}(1)=b \frac{d^{2} F_{n}}{d \eta^{2}}(1), \quad F_{n}(1)=0, \\
\frac{d \theta_{n}}{d \eta}(1)=-m_{4} \operatorname{Bi} \theta_{n}(1), \quad \frac{d H_{n}}{d \eta}(1)=-m_{4} \mathrm{Bi}_{n}(1) .
\end{gathered}
$$

The equations are solved iteratively and the series solutions for the velocity and temperature fields are given as

$$
\begin{aligned}
& F(\eta)=\frac{\eta\left(\eta^{2}+6 b-3\right)}{2-6 b}+\frac{\eta R m_{1}\left(\eta^{2}-1\right)}{280(3 b-1)^{3}} \\
& \times\left(3 \eta^{4} b-\eta^{4}+3 \eta^{2} b-\eta^{2}-18 b+2\right)+O\left(R^{2}\right), \\
& \theta(\eta)=\frac{3\left(4+m_{4} \mathrm{Bi}+\eta^{4} m_{4} \mathrm{Bi}\right) m_{3} \mathrm{Ec} \operatorname{Pr}}{4 m_{4} \mathrm{Bi}(3 b-1)^{2}}+O(R), \\
& H(\eta)=-\frac{3 m_{3} \operatorname{Ec} \operatorname{Pr}}{2 m_{4} \operatorname{Bi}(3 b-1)^{2}} \\
& \times\left(2 \eta^{2}+\frac{7}{2} m_{4} \mathrm{Bi} \eta^{2}+\frac{1}{6} \eta^{6} m_{4} \mathrm{Bi}+2 m_{4} \mathrm{Bi} \eta^{4} b\right. \\
& \left.-\eta^{4} m_{4} \mathrm{Bi}+12 m_{4} \mathrm{Bi} b^{2} \eta^{2}-12 m^{4} \mathrm{Bi} b \eta^{2}\right) \\
& -\frac{3 m_{3} \mathrm{Ec} \operatorname{Pr}}{2 m_{4}^{3} \mathrm{Bi}^{3}(3 b-1)^{2}\left(9 b^{2}-6 b+1\right)} \\
& \times\left(6+9 m_{4} \mathrm{Bi}-24 m_{4} \mathrm{Bi} b+36 m_{4} \mathrm{Bi}^{2}\right. \\
& \left.+4 m_{4}^{2} \mathrm{Bi}^{2}-15 m_{4}^{2} \mathrm{Bi}^{2} b+18 m_{4}^{2} \mathrm{Bi}^{2} b^{2}\right)+O(R),
\end{aligned}
$$

where $b=\lambda /(1-\varphi)^{2.5}$. We remark here that if we set the parameters $\varphi=0$ and $b=0$ in (29), we will recover the solution for the classical case of conventional fluid given in [1-4]. Using a computer symbolic algebra package (MAPLE), several terms of the above solution series in (29)-(31) are obtained. From (29)-(31) together with (20) and (23), we obtained the series solutions for the skin friction, Nusselt number, and axial pressure gradient as follows:

$$
\begin{aligned}
C_{f}=\frac{X}{(1-\varphi)^{2.5}}\left[\frac{3}{1-3 b}\right. & -\frac{3 R m_{1}}{35(3 b-1)^{3}} \\
& -\frac{R^{2} m_{1}^{2}\left(3465 b^{2}-1743 b+394\right)}{40425(3 b-1)^{5}} \\
& \left.+O\left(R^{3}\right)\right],
\end{aligned}
$$

$$
\begin{aligned}
A= & \frac{1}{(1-\varphi)^{2.5}} \\
& \times\left[\frac{3}{1-3 b}-\frac{9 R m_{1}\left(105 b^{3}-140 b^{2}+63 b-9\right)}{35(3 b-1)^{3}}\right. \\
& +\frac{R^{2} m_{1}^{2}\left(1155 b^{3}-1309 b^{2}+364 b-26\right)}{13475(3 b-1)^{5}} \\
& \left.+O\left(R^{3}\right)\right],
\end{aligned}
$$

$$
\begin{aligned}
\frac{k_{f}}{k_{\mathrm{nf}}} \mathrm{Nu}= & \frac{6 m_{3} \mathrm{Ec} \operatorname{Pr} G_{1}}{m_{4} \operatorname{Bi}(3 b-1)^{2}}+\frac{2 R m_{3} \mathrm{Ec} \operatorname{PrG}_{2}}{105 m_{4}^{2} \mathrm{Bi}^{2}(3 b-1)^{4}} \\
& +X^{2}\left(\frac{3 m_{3} \mathrm{Ec} \operatorname{Pr}}{(3 b-1)^{2}}+\frac{3 R m_{3} \mathrm{Ec} \operatorname{Pr} G_{3}}{35 m_{4} \operatorname{Bi}(3 b-1)^{4}}\right)+O\left(R^{2}\right),
\end{aligned}
$$

where the expression for $G_{i}, i=1,2,3$ is given in the appendix. We are aware that these power series solutions are valid for very small parameter values of $R$. However, using Hermite-Padé approximation technique (see Makinde [25]) that is based on the series summation and improvement method, the usability of the extended solution series is improved beyond small parameter values of $R$.

\section{Numerical Procedure}

An efficient finite difference approach based on Runge-KuttaFehlberg method with shooting technique [24] has been employed to numerically solve the coupled nonlinear ordinary differential equations (14)-(16) subject to the boundary conditions (17)-(18) for different values of governing parameters. The boundary value problem is first transformed into an initial value problem (IVP). Let

$$
\begin{aligned}
z_{1}=F, \quad z_{2}=\frac{d F}{d \eta}, & z_{3}=\frac{d^{2} F}{d \eta^{2}},
\end{aligned}
$$

Substituting (33) into (14)-(18), we obtain a system of first-order differential equations, respectively, as follows:

$$
\begin{gathered}
\frac{d z_{1}}{d \eta}=z_{2}, \quad \frac{d z_{2}}{d \eta}=z_{3}, \quad \frac{d z_{3}}{d \eta}=z_{4}, \\
\frac{d z_{4}}{d \eta}=m_{1} R\left(z_{2} z_{3}-z_{1} z_{4}\right), \quad \frac{d z_{5}}{d \eta}=z_{6}, \\
\frac{d z_{6}}{d \eta}=-m_{3} \operatorname{Ec} \operatorname{Pr} z_{3}^{2}+m_{2} R \operatorname{Pr}\left(2 z_{5} z_{2}-z_{1} z_{6}\right), \\
\frac{d z_{7}}{d \eta}=z_{8}, \quad \frac{d z_{8}}{d \eta}=-2 z_{5}-4 m_{3} \operatorname{Ec} \operatorname{Pr} z_{2}^{2}-m_{2} R \operatorname{Pr}\left(z_{1} z_{8}\right),
\end{gathered}
$$


TABLE 1: Thermophysical properties of the fluid phase (water) and nanoparticles [13-18].

\begin{tabular}{lccc}
\hline Physical properties & Fluid phase (Water) & $\mathrm{Cu}$ & $\mathrm{Al}_{2} \mathrm{O}_{3}$ \\
\hline$c_{p}(\mathrm{~J} / \mathrm{kgK})$ & 4179 & 385 & 765 \\
$\rho\left(\mathrm{kg} / \mathrm{m}^{3}\right)$ & 997.1 & 8933 & 3970 \\
$k(\mathrm{~W} / \mathrm{mK})$ & 0.613 & 400 & 40 \\
\hline
\end{tabular}

subject to the initial conditions:

$$
\begin{aligned}
& z_{1}(0)=0, \quad z_{2}(0)=s_{1}, \quad z_{3}(0)=0, \quad z_{4}(0)=s_{2}, \\
& z_{5}(0)=s_{3}, \quad z_{6}(0)=0, \quad z_{7}(0)=s_{4}, \quad z_{8}(0)=0 .
\end{aligned}
$$

By applying the shooting method with the NewtonRaphson algorithm to guess the unspecified conditions $s_{1}, s_{2}$, $s_{3}$, and $s_{4}$ in (35), the resulting initial value problem is then integrated numerically until the boundary conditions at $\eta=1$ are achieved. The step size is taken as $\Delta \eta=0.001$ and the convergence criteria were set to $10^{-7}$.

\section{Results and Discussion}

The flow of water base nanofluids containing $\mathrm{Cu}$ and $\mathrm{Al}_{2} \mathrm{O}_{3}$ as nanoparticles and their heat transfer characteristics in a symmetrically porous channel with Navier slip and convective cooling at the surface are investigated. The governing partial differential equations and the corresponding boundary conditions are converted into a set of nonlinear ordinary differential equations and tackled both analytically using the perturbation method coupled with series improvement technique and numerically using Runge-Kutta Fehlberg integration technique coupled with shooting scheme. Thermophysical properties of base fluid and nanoparticles are presented in Table 1. For pure water, the momentum diffusivity is dominant and convection is very effective in transferring within the fluid in comparison to pure conduction. Following [16-18], we take $\operatorname{Pr}=6.2$ in the numerical computation. Note that when $\varphi=0$, no nanoparticle is present in the based fluid (water). The solid volume fraction in the base fluid is taken as $\varphi=0$ to 0.3 (i.e., ranging from 0 to 30 percent). In order to get a clear insight into the entire flow structure and thermal development, we have assigned numerical values to other parameters encountered in the problem. Numerical solutions are displayed in Tables 2 and 3 together with Figures $2,3,4,5,6,7,8,9,10,11,12,13,14,15,16,17,18,19,20,21$, 22 , and 23 . The numerical values of suction driven normal velocity profile $(R=1)$ are displayed in Table 2 . In the absence of nanoparticles $(\varphi=0)$ and Navier slip $(\lambda=0)$ at the channel walls, the results agreed well with the one already in the literature (see [1-3]) for the flow of conventional fluid in a symmetrical porous wall channel. However, $\mathrm{Cu}-$ water nanofluid is affected more by the combined effects of suction and Navier slip at wall in comparison to $\mathrm{Al}_{2} \mathrm{O}_{3}$-water nanofluid. Table 3 shows the perfect agreement between the series solution and the numerical solution for the axial velocity profiles along the channel centerline with increasing
TABLE 2: Computation showing the normal velocity profiles for $R=$ 1.

\begin{tabular}{ccccc}
\hline & $-F(\eta)$ & $-F(\eta)$ & $-F(\eta)$ & $-F(\eta)$ \\
$\eta$ & $\begin{array}{c}\lambda=0, \varphi=0 \\
\text { Reference } \\
{[1-3]}\end{array}$ & $\begin{array}{c}\lambda=0, \varphi=0 \\
\text { Present }\end{array}$ & $\begin{array}{c}\varphi=0.1 \\
\text { Cu-water }\end{array}$ & $\begin{array}{c}\lambda=0.05, \\
\mathrm{Al}_{2} \mathrm{O}_{3} \text {-water }\end{array}$ \\
\hline 0.0 & 0.00000 & 0.000000 & 0.000000 & 0.000000 \\
0.1 & 0.14874 & 0.148739 & 0.160680 & 0.160920 \\
0.2 & 0.29455 & 0.294548 & 0.317732 & 0.318184 \\
0.3 & 0.43449 & 0.434493 & 0.467527 & 0.468132 \\
0.4 & 0.56564 & 0.565639 & 0.606428 & 0.607103 \\
0.5 & 0.68504 & 0.685042 & 0.730781 & 0.731419 \\
0.6 & 0.78974 & 0.789739 & 0.836887 & 0.837373 \\
0.7 & 0.87672 & 0.876724 & 0.920958 & 0.921192 \\
0.8 & 0.94292 & 0.942920 & 0.979045 & 0.978994 \\
0.9 & 0.98514 & 0.985137 & 1.006937 & 1.006713 \\
1.0 & 1.00000 & 1.000000 & 1.000000 & 1.000000 \\
\hline
\end{tabular}

TABLE 3: Computation showing the axial velocity profiles for $R=1$, $\lambda=0.05, X=1$, and $\eta=0$.

\begin{tabular}{lcccc}
\hline$\varphi$ & $\begin{array}{c}W(1,0) \\
\text { Cu-water } \\
\text { (series) }\end{array}$ & $\begin{array}{c}W(1,0) \\
\text { (numeriter } \\
\text { (numerical) }\end{array}$ & $\begin{array}{c}W(1,0) \\
\mathrm{Al}_{2} \mathrm{O}_{3} \text {-water } \\
\text { (series) }\end{array}$ & $\begin{array}{c}W(1,0) \\
\mathrm{Al}_{2} \mathrm{O}_{3} \text {-water } \\
\text { (numerical) }\end{array}$ \\
\hline 0.00 & 1.581405 & 1.581405 & 1.581405 & 1.581405 \\
0.01 & 1.583733 & 1.583733 & 1.584084 & 1.584084 \\
0.05 & 1.594688 & 1.594688 & 1.596218 & 1.596218 \\
0.10 & 1.612850 & 1.612850 & 1.615303 & 1.615303 \\
0.15 & 1.637660 & 1.637660 & 1.640343 & 1.640343 \\
0.20 & 1.672037 & 1.672037 & 1.674097 & 1.674097 \\
0.25 & 1.721196 & 1.721196 & 1.721395 & 1.721395 \\
0.30 & 1.795420 & 1.795420 & 1.791485 & 1.791485 \\
\hline
\end{tabular}

concentration of nanoparticles for both $\mathrm{Cu}$-water and $\mathrm{Al}_{2} \mathrm{O}_{3}$ water nanofluids.

5.1. Velocity Profiles with Parameter Variation. The effects of parameter variation on both the axial and normal velocity components are displayed in Figures 2-9. Generally, it is interesting to note that the effect of Navier slip is to cause flow reversal at the channel walls. In Figure 2, it is observed that $\mathrm{Cu}$-water moves faster along the channel centerline region and subjected to higher flow reversal at the wall as compared to $\mathrm{Al}_{2} \mathrm{O}_{3}$-water in the presence of suction. With $\mathrm{Cu}$-water as the working nanofluid, it is observed that increasing nanoparticles volume fraction concentration from 0 to $30 \%$ increases both the axial velocity along the centerline region and the flow reversal at the channel walls as shown in Figure 3. Similar trend is observed in Figures 4-5 with a growing suction parameter and Navier slip parameter. Figures 6-9 show the nanofluids normal velocity profiles. With suction and Navier slip, the $\mathrm{Cu}$-water moves faster to the wall as compared to $\mathrm{Al}_{2} \mathrm{O}_{3}$-water as illustrated in Figure 6 . 


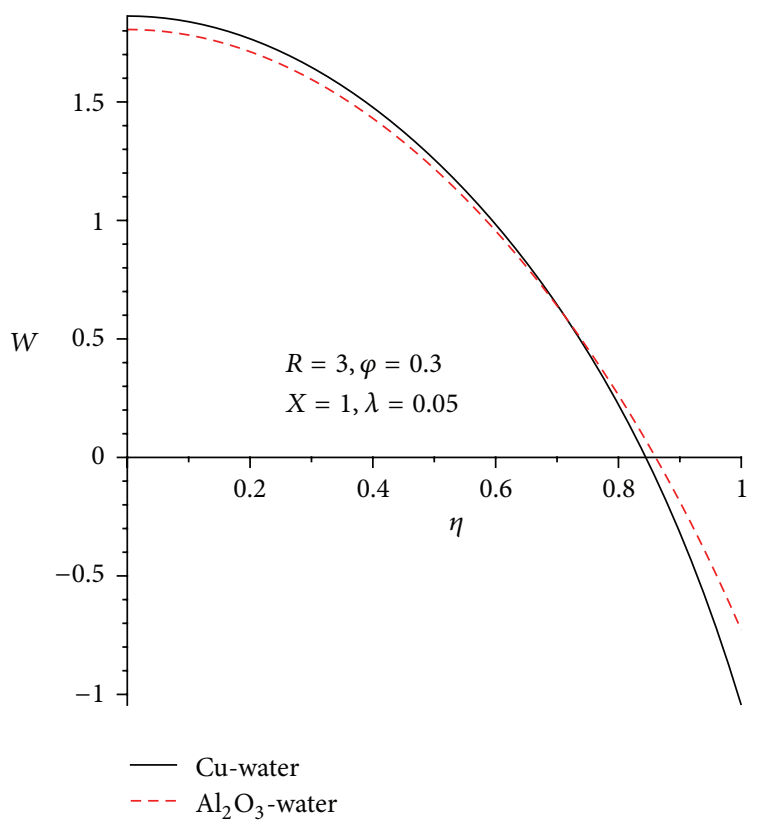

FIGURE 2: Nanofluids axial velocity profiles.

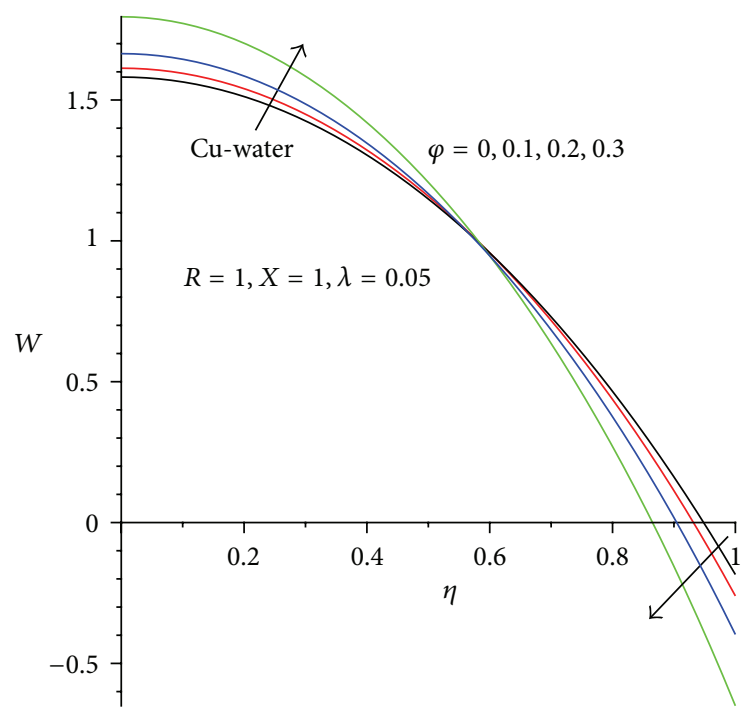

Figure 3: Axial velocity profiles with increasing $\varphi$.

A further increase in normal velocity towards the walls is observed with a growing in suction parameter, Navier slip parameter, and nanoparticles volume fraction as shown in Figures 7-9.

5.2. Temperature Profiles with Parameter Variation. Figures 10-16 illustrate the nanofluids temperature profiles across the channel with different parameter variation. Generally, a decrease in the fluid temperature near the channel walls is observed due to convective heat loss to ambient surrounding. It is noteworthy that the temperature of $\mathrm{Cu}$-water nanofluid is generally higher than that of $\mathrm{Al}_{2} \mathrm{O}_{3}$-water nanofluid under

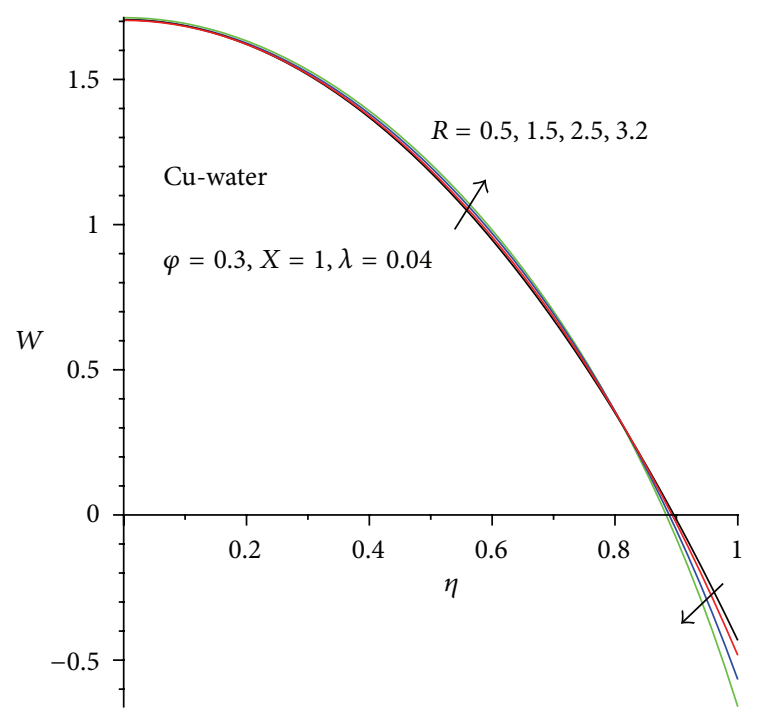

Figure 4: Axial velocity profiles with increasing $R$.

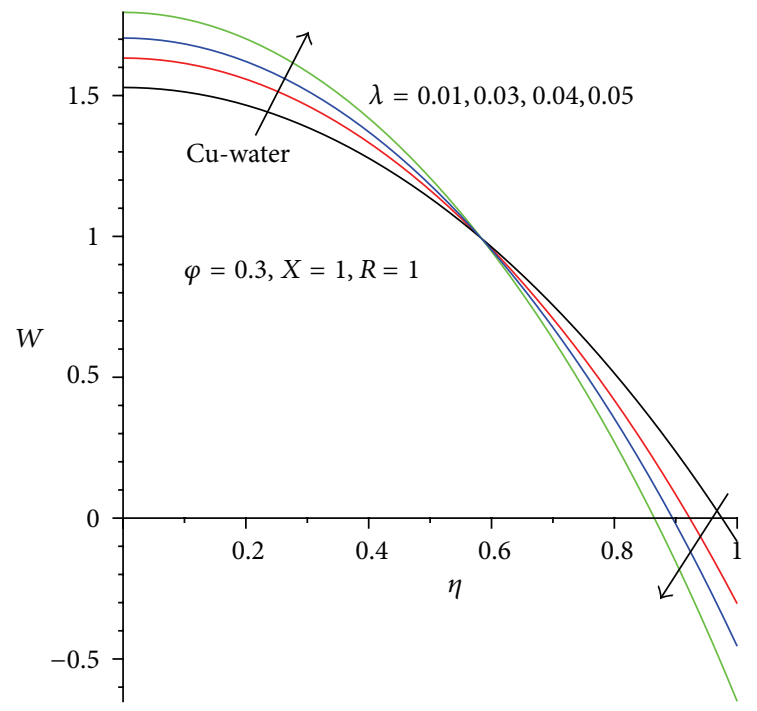

FIGURE 5: Axial velocity profiles with increasing $\lambda$.

the same flow condition as shown in Figure 10. In Figure 11, it is observed that the nanofluid temperature decreases with growing in nanoparticles volume fraction. Similar effect of a decrease in nanofluid temperature is observed in Figure 12 with $\mathrm{Cu}$-water as working nanofluid as the Biot number increases. This is expected, since an increase in Biot number indicates a rise in convective cooling due to heat loss to the ambient surrounding from the channel walls. Meanwhile, a combine increase in the suction, Navier slip, and viscous dissipation as shown in Figures 13-15 causes an increase in the nanofluid temperature. This may be attributed to the fact that $R, \lambda$, and Ec increase the internal heat generation within the fluid due velocity gradient increases, leading to a rise in temperature. Figure 16 elucidates the temperature profiles with increasing axial distance along the channel. 


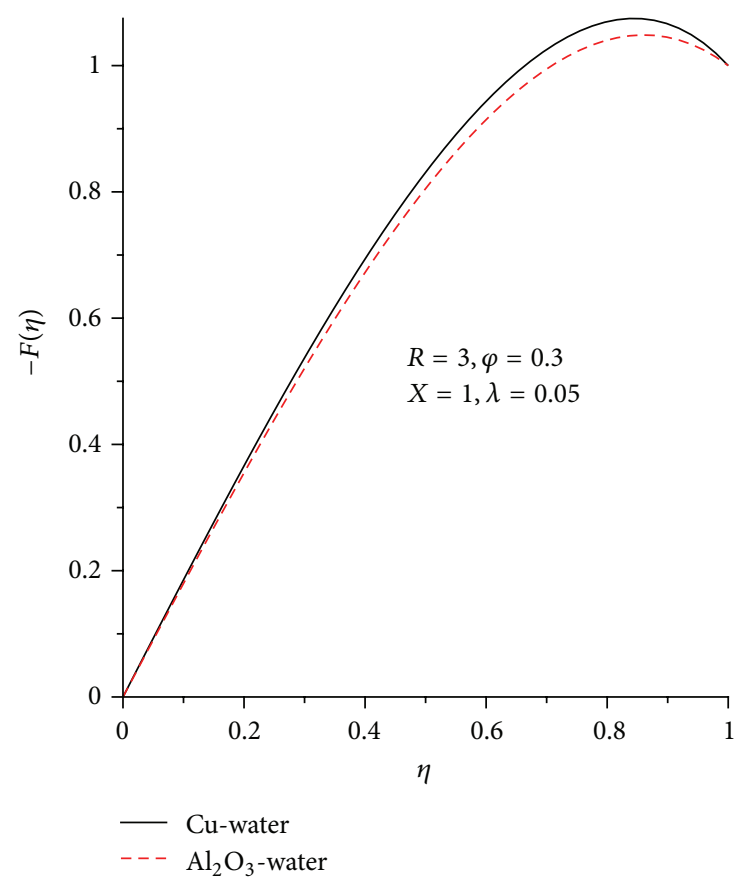

FIGURE 6: Nanofluids normal velocity profiles.

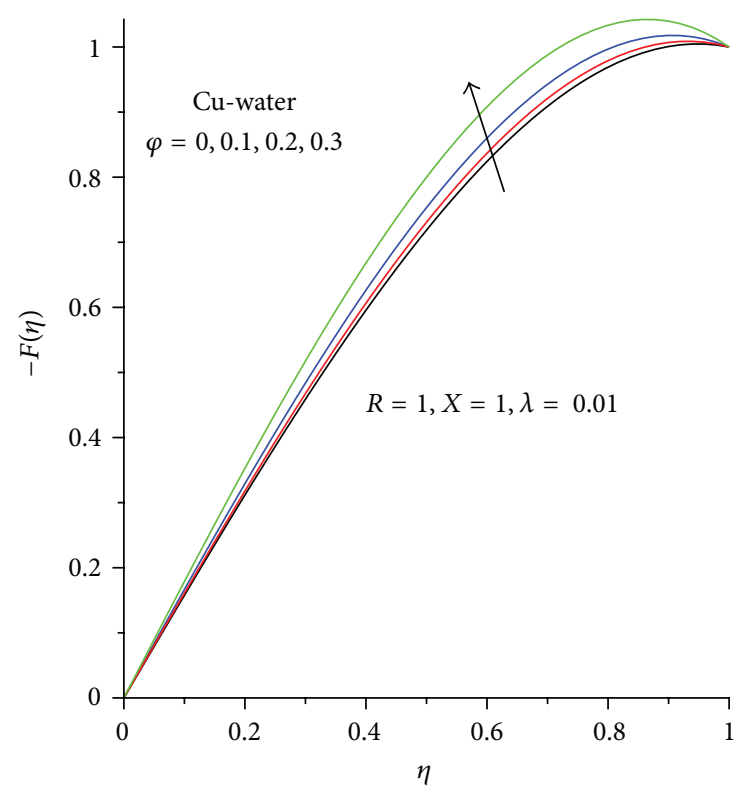

FIGURE 7: Normal velocity profiles with increasing $\varphi$.

The nanofluid temperature decreases within the channel centerline region and increases near the wall region with increasing axial distance. Moreover, it is interesting to note that at point $\eta=0.5$ within the channel, the nanofluid temperature is independent of the axial distance.

5.3. Skin Friction, Pressure Gradient, and Nusselt Number. Figures 17-18 depict the skin friction profiles for both $\mathrm{Cu}-$ water and $\mathrm{Al}_{2} \mathrm{O}_{3}$-water nanofluids at the channel walls.

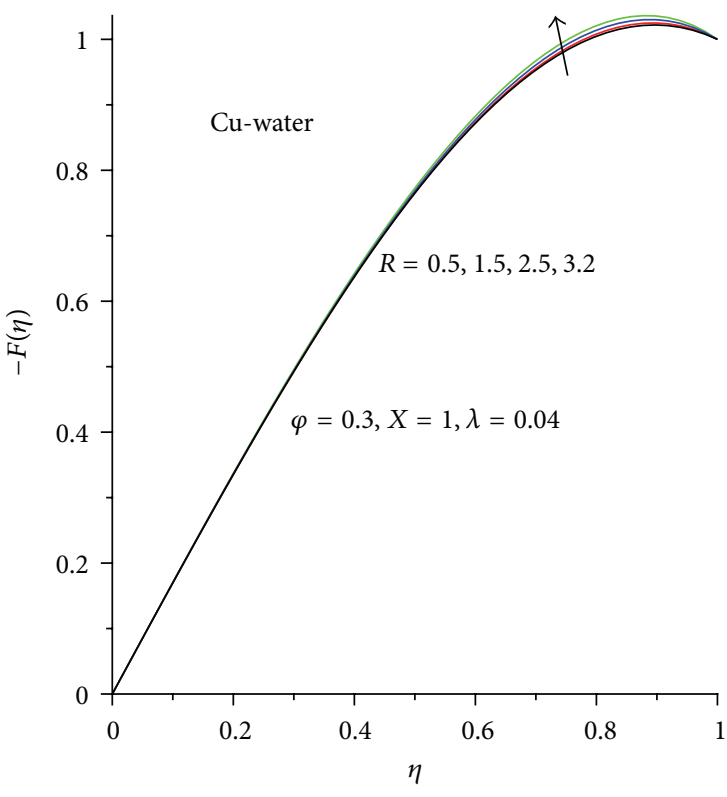

FIGURE 8: Normal velocity profiles with increasing $R$.

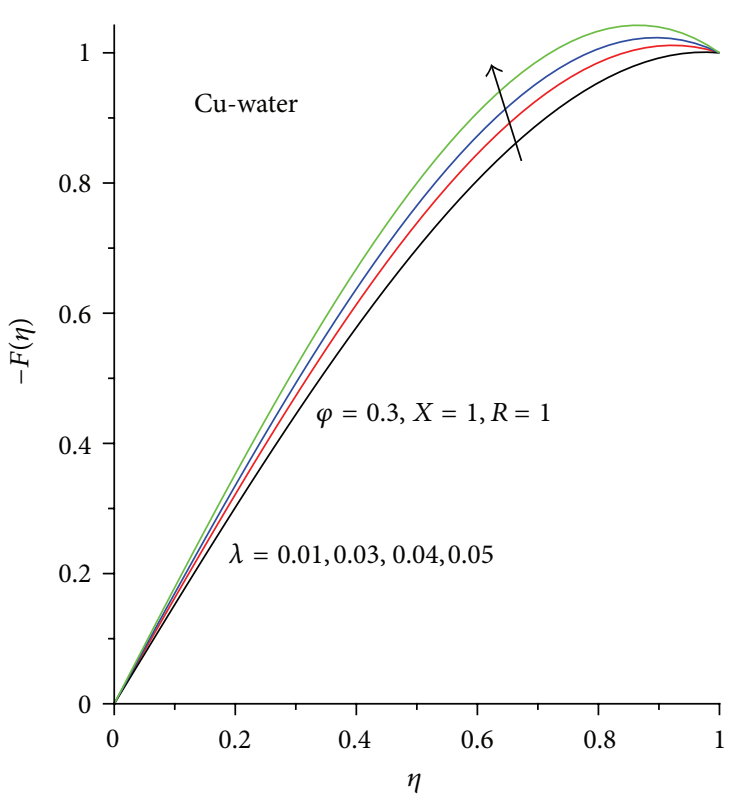

FIgURE 9: Normal velocity profiles with increasing $\lambda$.

The skin friction generally increases with an increase in nanoparticles volume fraction; however, it is noticed that the skin friction produced by $\mathrm{Cu}$-water is more intense than the one produced by $\mathrm{Al}_{2} \mathrm{O}_{3}$-water as shown in Figure 17. This is expected since the velocity gradient of $\mathrm{Cu}$-water near the channel walls is higher than that of $\mathrm{Al}_{2} \mathrm{O}_{3}$-water. In Figure 18, it is observed that the skin friction generally increases with an increase in Navier slip. Meanwhile, a growing in suction $(R>0)$ increases the skin friction, while a growing in injection $(R<0)$ decreases the skin friction. The pressure drop along the channel is illustrated in Figures 19 and 20. 


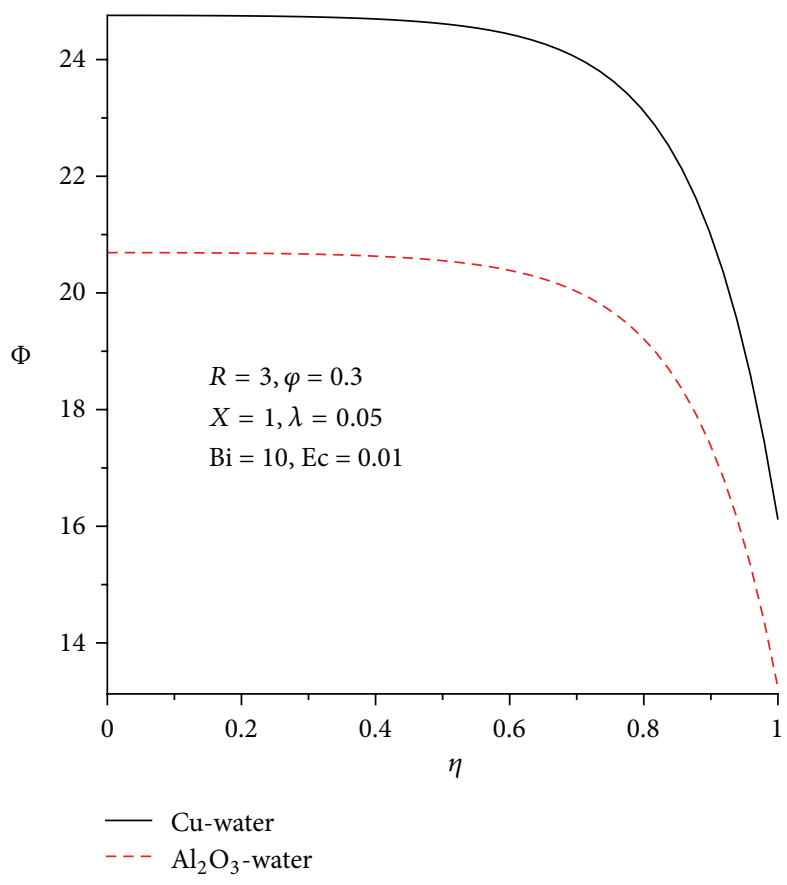

FIGURE 10: Nanofluids temperature profiles.

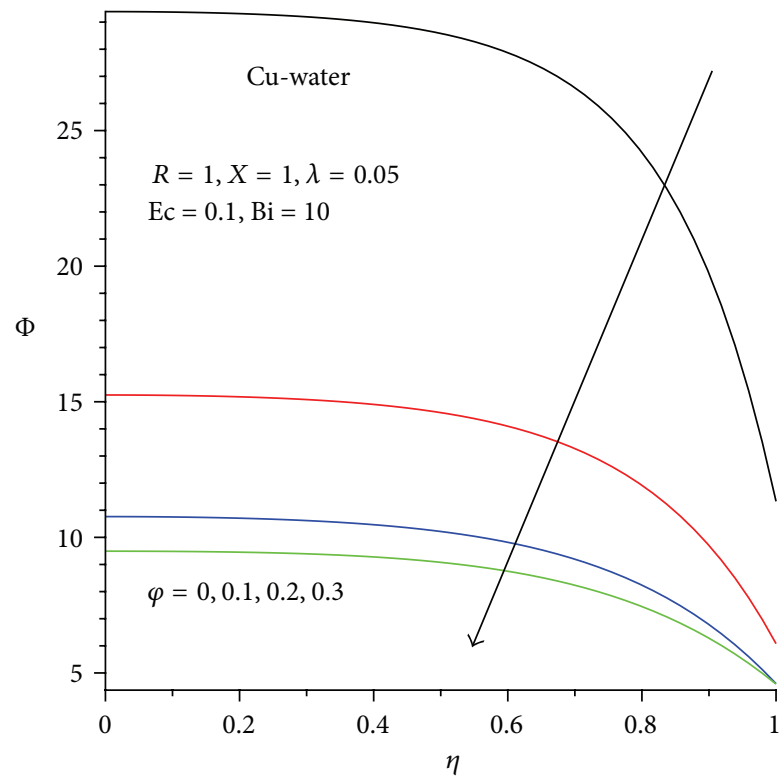

FIgURE 11: Temperature profiles with increasing $\varphi$.

For both $\mathrm{Cu}$-water and $\mathrm{Al}_{2} \mathrm{O}_{3}$-water nanofluids, the pressure drop increases with increasing nanoparticles volume fraction. Interestingly, the pressure drop produced by $\mathrm{Al}_{2} \mathrm{O}_{3}$-water is slightly higher than that of $\mathrm{Cu}$-water as shown in Figure 19. Figure 20 shows a general increase in pressure drop with a rise in Navier slip. A growing in suction $(R>0)$ decreases the pressure drop, while a growing in injection $(R<0)$ increases the pressure drop along the channel. Figures $21-23$ elucidate the heat transfer rate at the channel walls with different

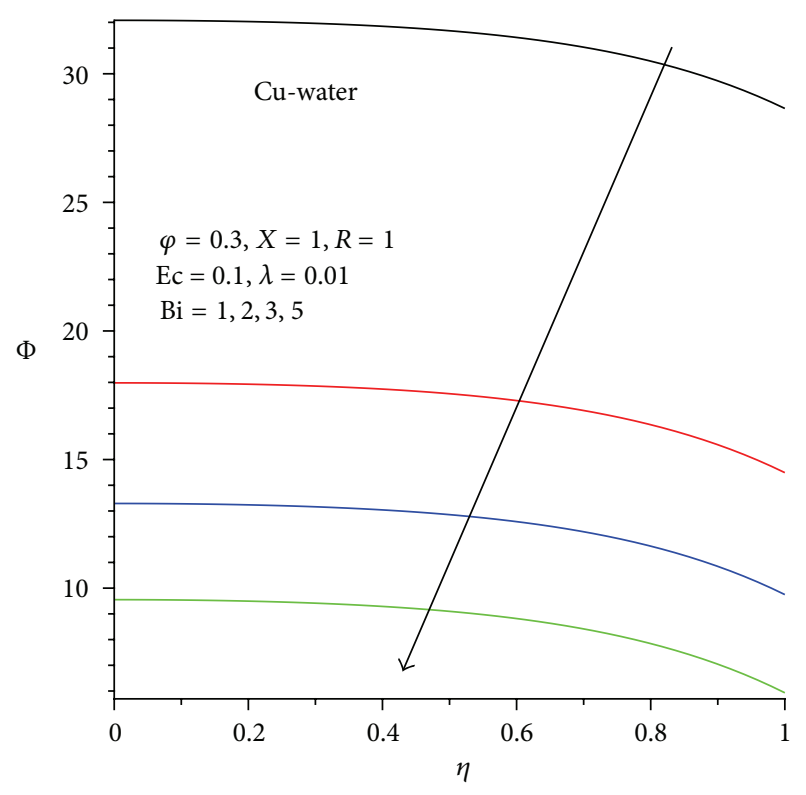

FIGURE 12: Temperature profiles with increasing Bi.

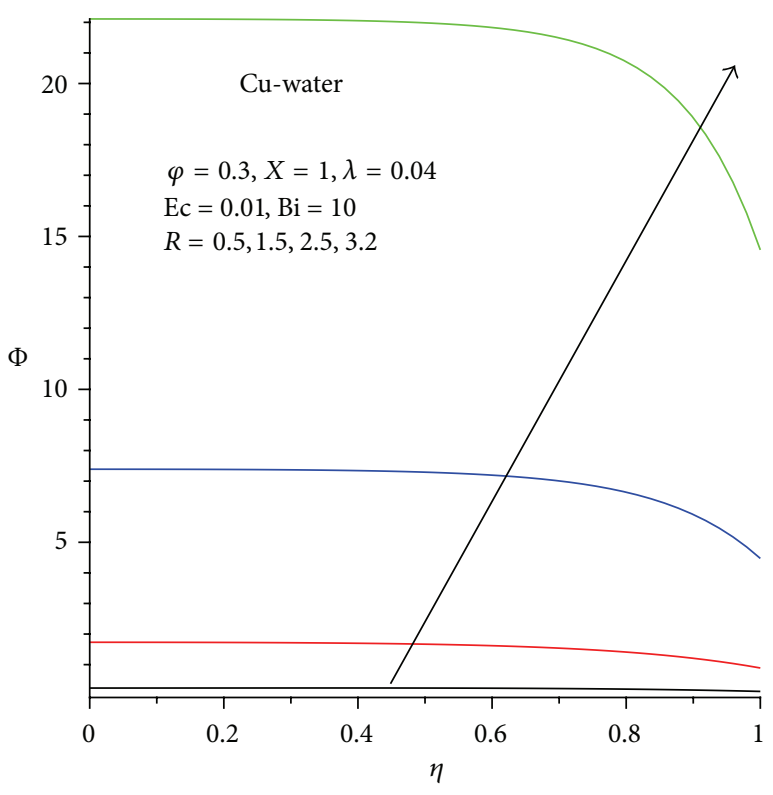

FIGURE 13: Temperature profiles with increasing $R$.

parameter variation. It is observed that the wall heat transfer rate $(\mathrm{Nu})$ decreases with an increase in the nanoparticles volume fraction as shown in Figure 21. A slight increase in $\mathrm{Al}_{2} \mathrm{O}_{3}$-water Nusselt number is noticed as compared to $\mathrm{Cu}$-water Nusselt number. In Figure 22, it is seen that the increase in the Navier slip parameter results in increase in Nusselt number. This may be due to a rise in the nanofluid temperature gradient at the channel walls. Meanwhile, as the suction increases, the heat flux at the wall increases, while a decrease in wall heat is observed with a rise in injection. The strength of the wall heat flux is enhanced with increasing axial distance, viscous dissipation, and convective cooling as 


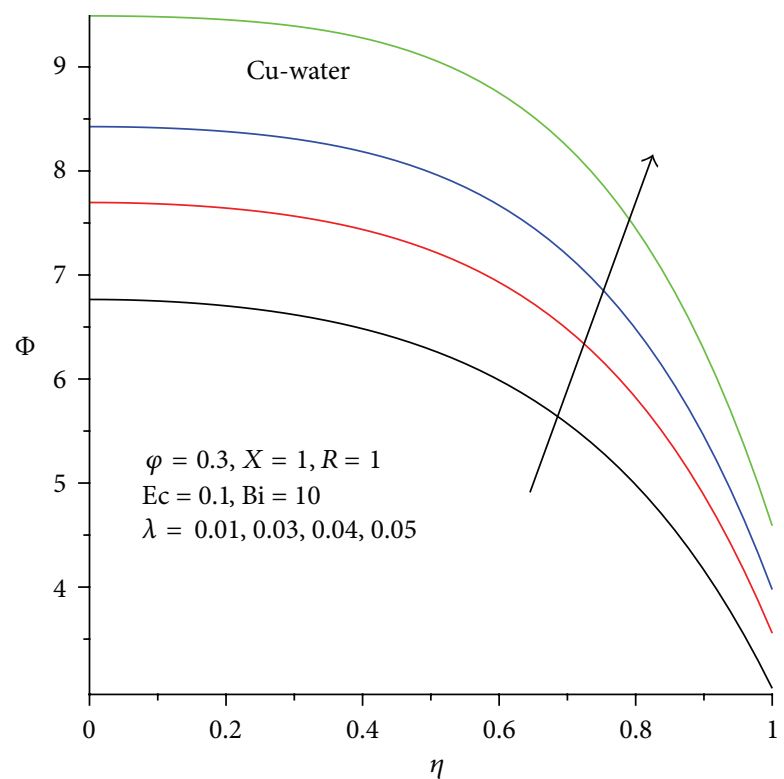

Figure 14: Temperature profiles with increasing $\lambda$.

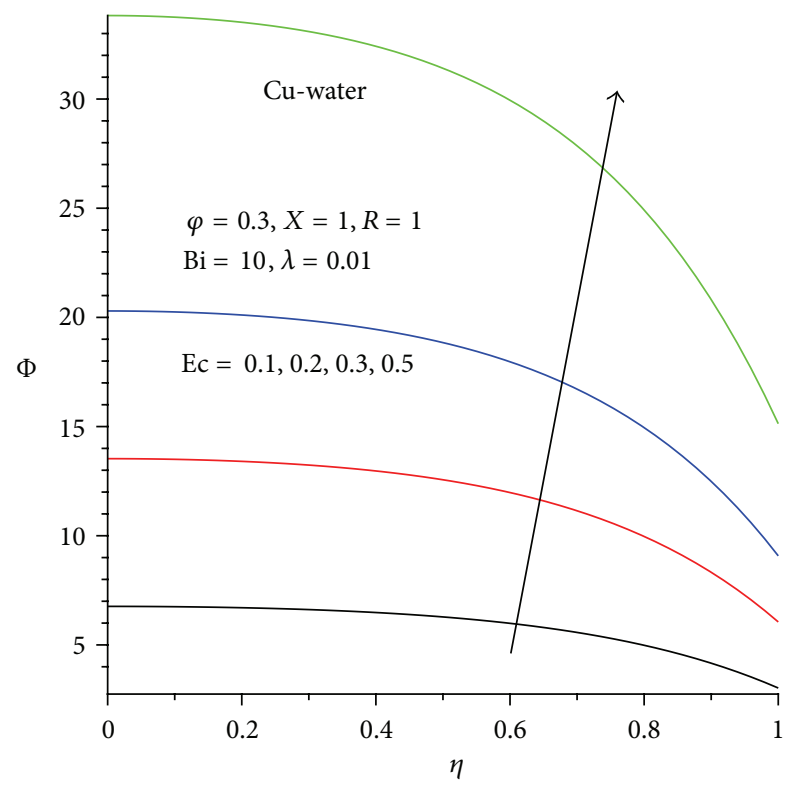

FIGURE 15: Temperature profiles with increasing Ec.

illustrated in Figure 23. This can be attributed to a rise in the temperature gradient due to convective heat exchange with the ambient along the channel walls.

\section{Conclusion}

The combined effects of viscous dissipation, Navier slip, and convective cooling on Berman flow and heat transfer of water base nanofluids containing $\mathrm{Cu}$ and $\mathrm{Al}_{2} \mathrm{O}_{3}$ as nanoparticles are investigated. The nonlinear model problem is tackled both analytically using perturbation series method and numerically using Runge-Kutta Fehlberg integration

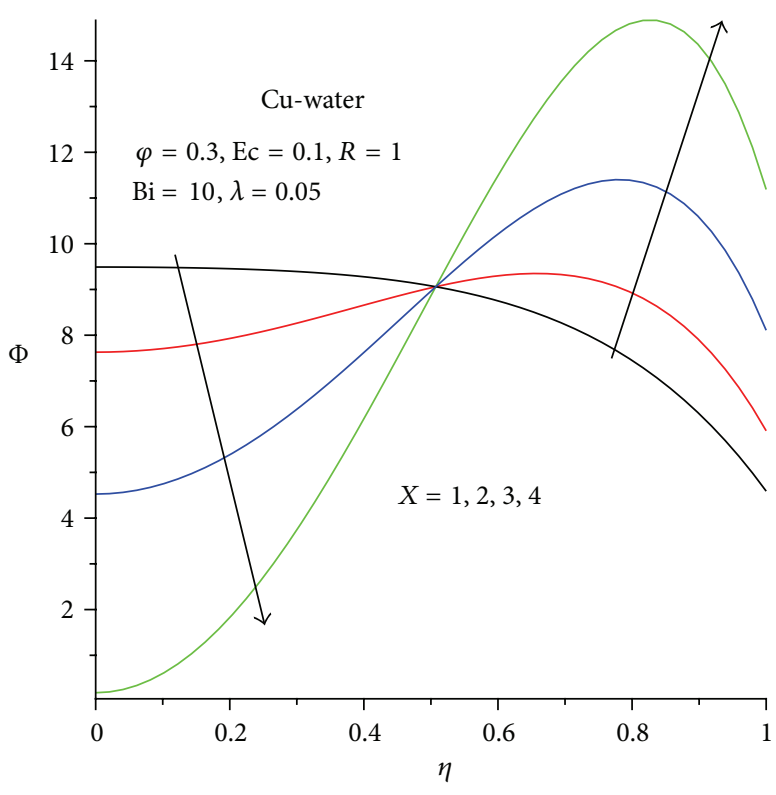

Figure 16: Temperature profiles with increasing $X$.

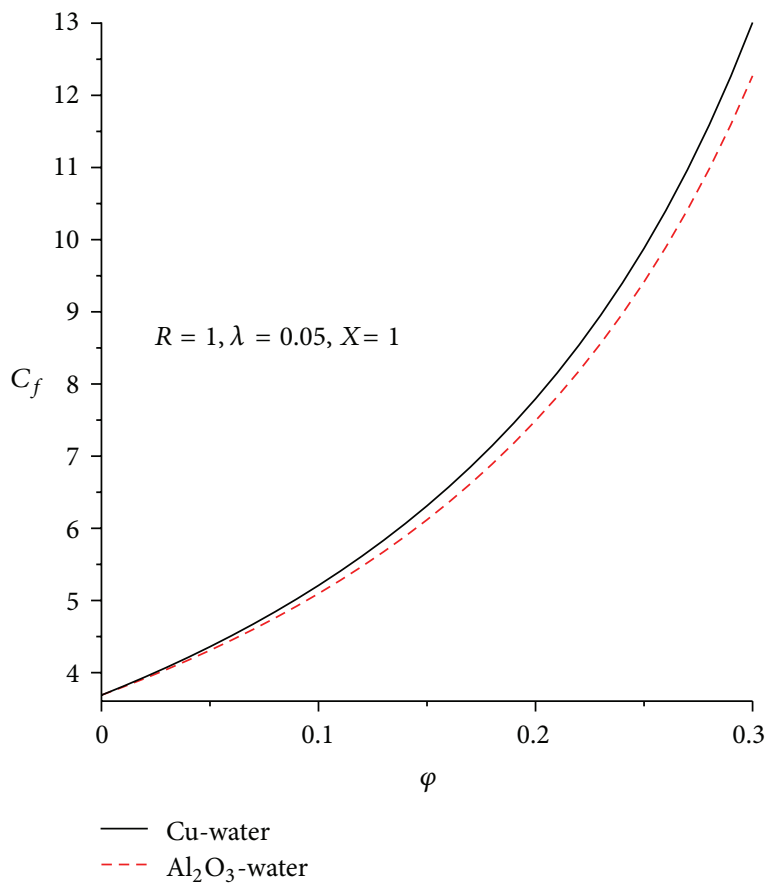

FIGURE 17: Skin friction with increasing $\varphi$.

technique coupled with shooting scheme. We summarize below some of the essential features of physical interest from the above analysis.

(i) $\mathrm{Cu}$-water nanofluid moves faster with enhanced flow reversal at the walls as compared to $\mathrm{Al}_{2} \mathrm{O}_{3}$-water nanofluid.

(ii) Nanofluids velocity and flow reversal at the walls increase with suction, $\lambda$, and $\varphi$. 


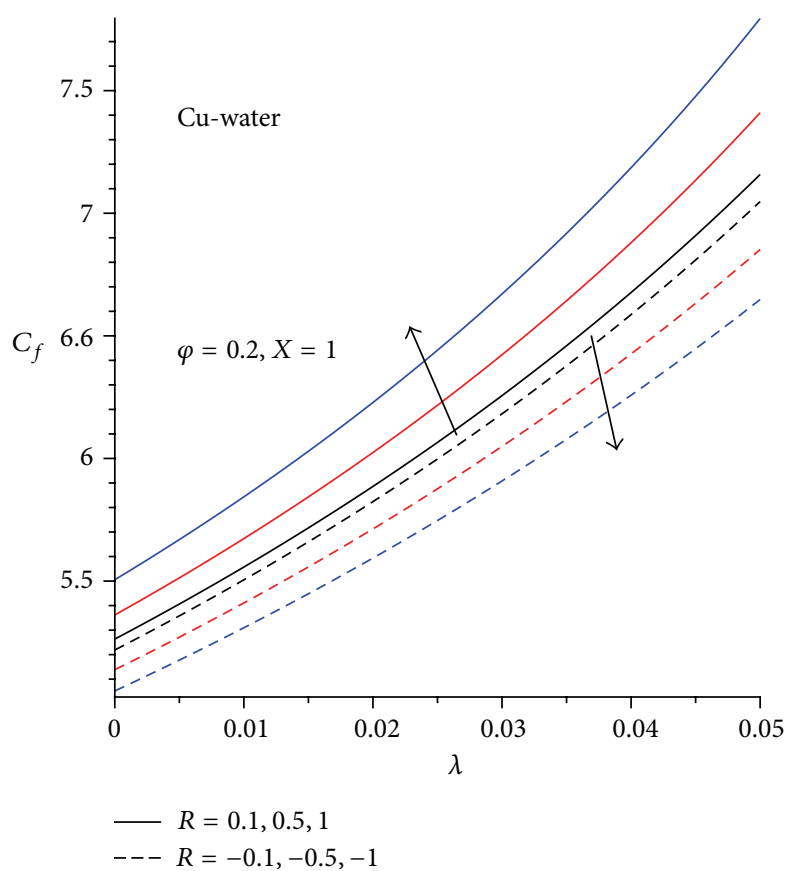

FIGURE 18: Skin friction with increasing $R$ and $\lambda$.

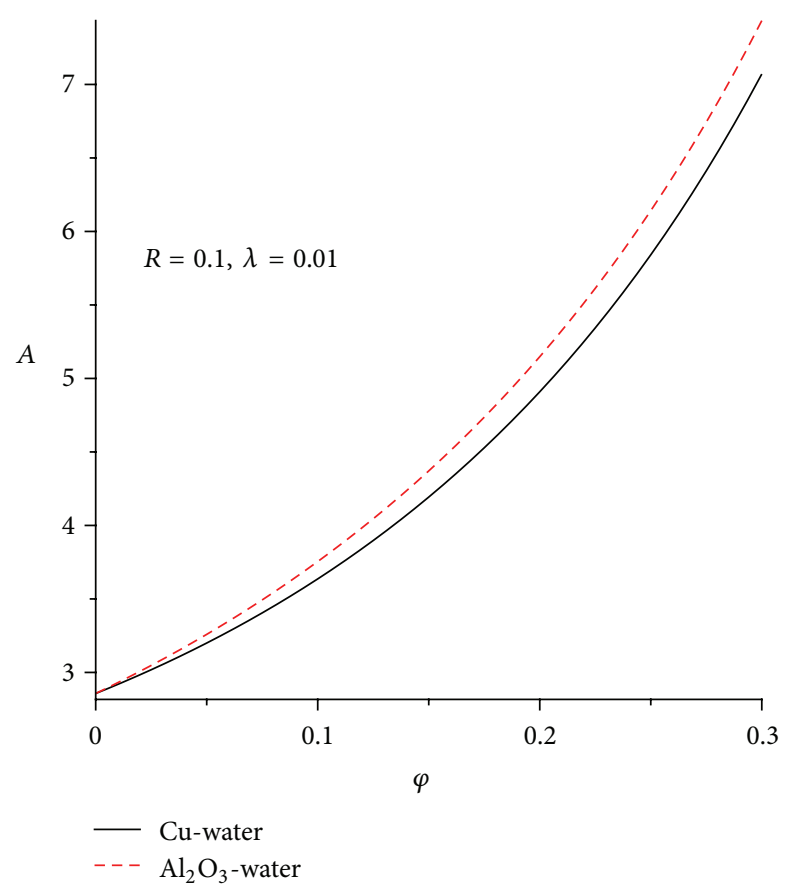

FIgURE 19: Axial pressure gradient with increasing $\varphi$.

(iii) $\mathrm{Cu}$-water produced higher temperature as compared to $\mathrm{Al}_{2} \mathrm{O}_{3}$-water. The nanofluids temperature increases with suction, $\lambda$, and $\mathrm{Ec}$, but it decreases with $\mathrm{Bi}$ and $\varphi$.

(iv) The skin friction produced by $\mathrm{Cu}$-water is more intense than that of $\mathrm{Al}_{2} \mathrm{O}_{3}$-water. The skin friction

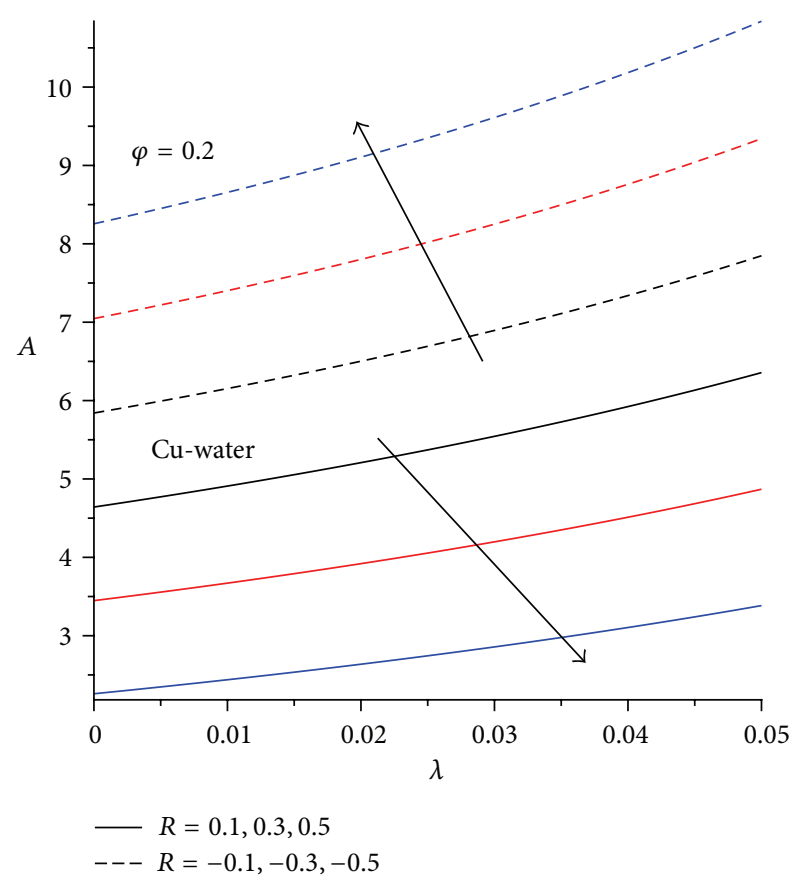

FIgURE 20: Axial pressure gradient with increasing $R$ and $\lambda$.

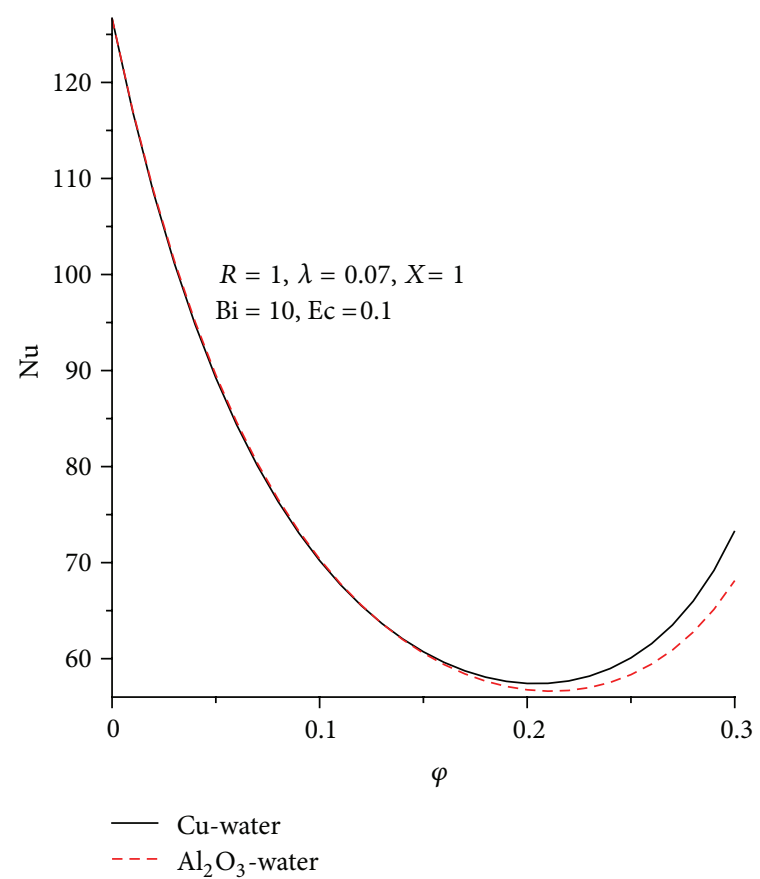

FIgURE 21: Nusselt number with increasing $\varphi$.

increases with suction $(R>0), \lambda$, and $\varphi$ but decreases with injection $(R<0)$.

(v) The pressure drop produced by $\mathrm{Al}_{2} \mathrm{O}_{3}$-water in more than that of $\mathrm{Cu}$-water. The pressure drop is enhanced by injection, $\lambda$, and $\varphi$ but decreases by suction. 


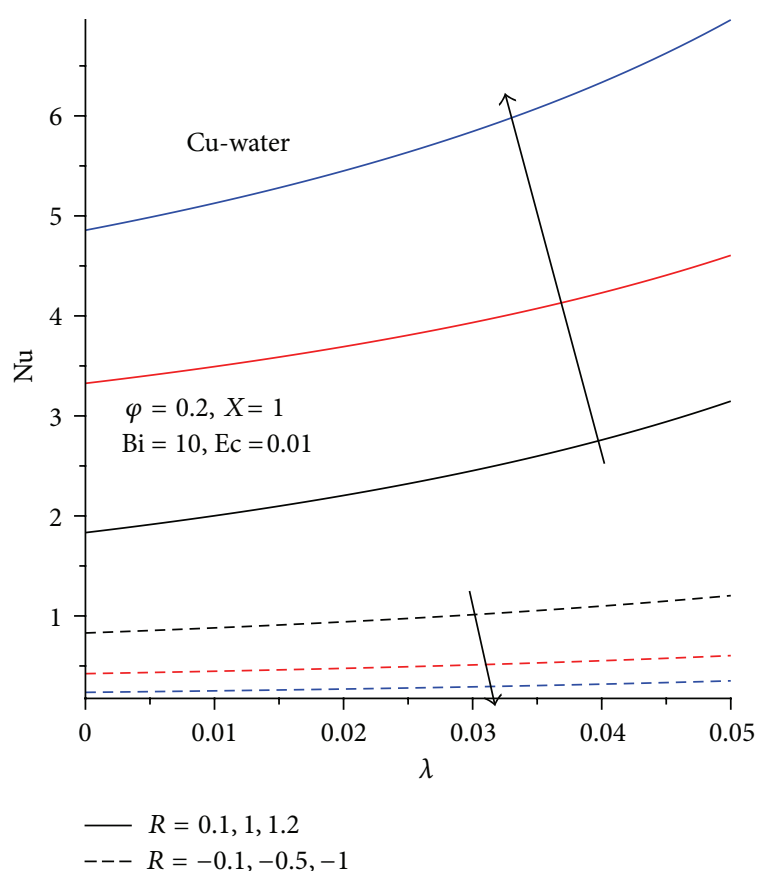

FIGURE 22: Nusselt number with increasing $R$ and $\lambda$.

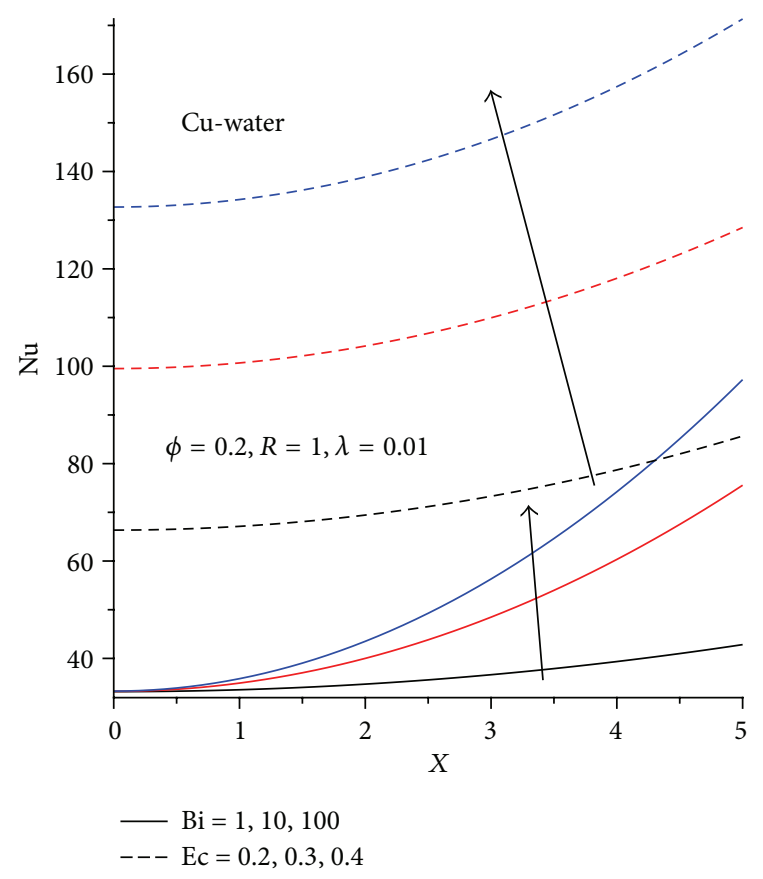

Figure 23: Nusselt number with increasing $X, \mathrm{Bi}$, and Ec.

(vi) The Nusselt number increases with suction, $\lambda, B i$, $\mathrm{Ec}$, and $X$, but it decreases with injection and $\varphi$. A slight increase in $\mathrm{Nu}$ for $\mathrm{Al}_{2} \mathrm{O}_{3}$-water is noticed as compared to $\mathrm{Cu}$-water.

\section{Appendix}

$$
\begin{gathered}
G_{1}=1+m_{4} \mathrm{Bi}-4 m_{4} \mathrm{Bi} b+6 m_{4} \mathrm{Bi}^{2} \\
G_{2}=-2 m_{1} m_{4}^{2} \mathrm{Bi}^{4}-3780 m_{2} \operatorname{Pr} b+5670 m_{2} \operatorname{Pr} b^{2}+630 m_{2} \operatorname{Pr} \\
+24 m_{1} m_{4}^{2} \mathrm{Bi}^{2} b+232 m_{2} m_{4}^{2} \mathrm{Pr} \mathrm{Bi}^{2}-3294 m_{2} m_{4} \operatorname{Pr} \mathrm{Bi} b \\
+4536 m_{2} m_{4} \operatorname{PrBi}^{2}-1875 m_{2} m_{4}^{2} \mathrm{Bi}^{2} \operatorname{Pr} b \\
+5805 m_{2} m_{4}^{2} \operatorname{Pr}^{2} \mathrm{Bi}^{2}-8694 m_{2} m_{4}^{2} \operatorname{Pr~Bi}^{2} b^{3} \\
+5670 m_{2} m_{4}^{2} \operatorname{PrBi}^{2} b^{4}+54 m_{1} m_{4} \mathrm{Bi} b \\
+594 m_{2} m_{4} \operatorname{Pr} \mathrm{Bi} \\
G_{3}=6 m_{1} m_{4} \mathrm{Bi} b+70 m_{2} \operatorname{Pr}-135 m_{2} m_{4} \operatorname{Pr} \mathrm{Bi} b \\
+24 m_{2} m_{4} \operatorname{Pr} \mathrm{Bi}-420 m_{2} \operatorname{Pr} b+630 m_{2} \operatorname{Pr}^{2} \\
+189 m_{2} m_{4} \operatorname{Pr} \mathrm{Bi} b^{2}
\end{gathered}
$$

\section{Nomenclature}

$(u, v)$ : Velocity components

$(x, y)$ : Coordinates

$k_{\mathrm{nf}}$ : Nanofluid thermal conductivity

Pr: $\quad$ Prandtl number

Bi: local Biot number

$T_{w}$ : Ambient temperature

$F: \quad$ Dimensionless stream function

$V: \quad$ Wall suction velocity

T: $\quad$ Temperature

$H$ : Dimensionless temperature

$R: \quad$ Reynolds number

$c_{p}$ : Specific heat at constant pressure

$k_{s}$ : Solid fraction thermal conductivity

$k_{f}$ : Base fluid thermal conductivity

$W: \quad$ Dimensionless axial velocity

Ec: Eckert number

$X: \quad$ Dimensionless axial coordinate

A: Axial pressure gradient coefficient

a: Channel half width

$\mathrm{Nu}$ : Nusselt number

$C_{f}$ : Skin friction coefficient.

\section{Greek Symbols}

$\psi:$ Stream function

$\theta$ : Dimensionless temperature

$\mu_{\text {nf: }}$ Nanofluid dynamic viscosity

$\alpha_{\mathrm{nf}}$ : Nanofluid thermal diffusivity

$\eta$ : Dimensionless normal coordinate

$\rho_{\mathrm{nf}}$ : Nanofluid density

$\rho_{s}$ : Solid fraction density

$v_{f}$ : Base fluid kinematic viscosity

$\mu_{f}$ : Base fluid dynamic viscosity

$\varphi$ : Solid volume fraction parameter 


\author{
$\rho_{f}$ : Base fluid density \\ $\beta$ : Slip coefficient \\ $\lambda$ : Navier slip parameter \\ $\Omega$ : Vorticity \\ $\bar{\psi}$ : Dimensionless stream function \\ $\bar{\Omega}:$ Dimensionless vorticity \\ $\Phi:$ Dimensionless temperature.
}

\section{Conflict of Interests}

The authors declare that there is no conflict of interests.

\section{References}

[1] A. S. Berman, "Laminar flow in channels with porous walls," Journal of Applied Physics, vol. 24, pp. 1232-1235, 1953.

[2] J. R. Sellars, "Laminar flow in channels with porous walls at high suction Reynolds numbers," Journal of Applied Physics, vol. 26, no. 4, pp. 489-490, 1955.

[3] S. W. Yaun, "Further investigation of laminar flow in channels with porous walls," Journal of Applied Physics, vol. 27, no. 3, pp. 267-269, 1956.

[4] R. M. Terrill, "An exact solution for flow in a porous pipe," Journal of Applied Mathematics and Physics, vol. 33, no. 4, pp. 547-552, 1982.

[5] R. M. Terrill, "Laminar flow in a porous tube," Journal of Fluids Engineering, vol. 105, pp. 303-306, 1983.

[6] M. M. Sorour, M. A. Hassab, and S. Estafanous, "Developing laminar flow in a semiporous two-dimensional channel with nonuniform transpiration," International Journal of Heat and Fluid Flow, vol. 8, pp. 44-54, 1987.

[7] M. B. Zaturska, P. G. Drazin, and W. H. H. Banks, "On the flow of a viscous fluid driven along a channel by suction at porous walls," Fluid Dynamics Research, vol. 4, no. 3, pp. 151-178, 1988.

[8] R. J. Pederson and R. B. Kinney, "Entrance-region heat transfer for laminar flow in porous tubes," International Journal of Heat and Mass Transfer, vol. 14, pp. 159-161, 1971.

[9] O. D. Makinde, "Extending the utility of perturbation series in problems of laminar flow in a porous pipe and a diverging channel," Australian Mathematical Society B. Applied Mathematics, vol. 41, no. 1, pp. 118-128, 1999.

[10] G. D. Raithby, "Laminar heat transfer in the thermal entrance region of circular tubes and two-dimensional rectangular ducts with wall suction and injection," International Journal of Heat and Mass Transfer, vol. 14, pp. 224-243, 1971.

[11] S. U. S. Choi, "Enhancing thermal conductivity of fluids with nanoparticles," in Proceedings of the ASME International Mechanical Engineering Congress and Exposition, pp. 99-105, ASME, San Francisco, Calif, USA, 1995.

[12] B. C. Pak and Y. I. Cho, "Hydrodynamic and heat transfer study of dispersed fluids with submicron metallic oxide particles," Experimental Heat Transfer, vol. 11, no. 2, pp. 151-170, 1998.

[13] D. Wen and Y. Ding, "Experimental investigation into the pool boiling heat transfer of aqueous based c-alumina nanofluids," Journal of Nanoparticle Research, vol. 7, no. 2, pp. 265-274, 2005.

[14] J. Wang, J. Zhu, X. Zhang, and Y. Chen, "Heat transfer and pressure drop of nanofluids containing carbon nanotubes in laminar flows.," Experimental Thermal and Fluid Science, vol. 44, pp. 716-721, 2013.
[15] Y. Xuan and Q. Li, "Investigation on convective heat transfer and flow features of nanofluids," Journal of Heat Transfer, vol. 125, no. 1, pp. 151-155, 2003.

[16] H. F. Oztop and E. Abu-Nada, "Numerical study of natural convection in partially heated rectangular enclosures filled with nanofluids," International Journal of Heat and Fluid Flow, vol. 29, pp. 1326-1336, 2008.

[17] O. D. Makinde, "Computational modelling of nanofluids flow over a convectively heated unsteady stretching sheet," Current Nanoscience, vol. 9, pp. 673-678, 2013.

[18] S. Kakac and A. Pramuanjaroenkij, "Review of convective heat transfer enhancement with nanofluids," International Journal of Heat and Mass Transfer, vol. 52, no. 13/14, pp. 3187-3196, 2009.

[19] P. Huang and K. S. Breuer, "Direct measurement of slip length in electrolyte solutions," Physics of Fluids, vol. 19, Article ID 028104, 2007.

[20] M. J. Martin and D. I. Boyd, "Momentum and heat transfer in a laminar boundary layer with slip flow," Journal of Thermophysics and Heat Transfer, vol. 20, no. 4, pp. 710-719, 2006.

[21] C. L. M. H. Navier, "Mémoire sur les lois du mouvement des fluides," Mémoires de l'Académie Royale des Sciences de l'Institut de France, vol. 6, pp. 389-440, 1823.

[22] H. C. Brinkman, "The viscosity of concentrated suspensions and solution," The Journal of Chemical Physics, vol. 20, pp. 571581, 1952.

[23] J. C. Maxwell, Electricity and Magnetism, Clarendon, Oxford, UK, 3rd edition, 1904.

[24] T. Y. Na, Computational Methods in Engineering Boundary Value Problems, Academic Press, New York, NY, USA, 1979.

[25] O. D. Makinde, "Hermite-Padé approach to thermal radiation effect on inherent irreversibility in a variable viscosity channel flow," Computers \& Mathematics with Applications, vol. 58, no. 11-12, pp. 2330-2338, 2009. 


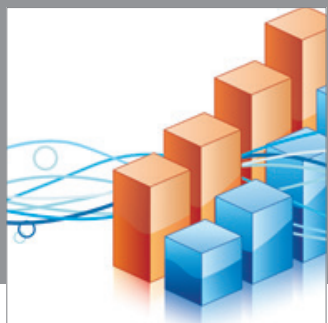

Advances in

Operations Research

mansans

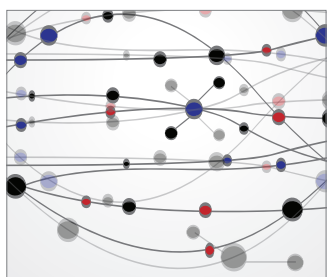

The Scientific World Journal
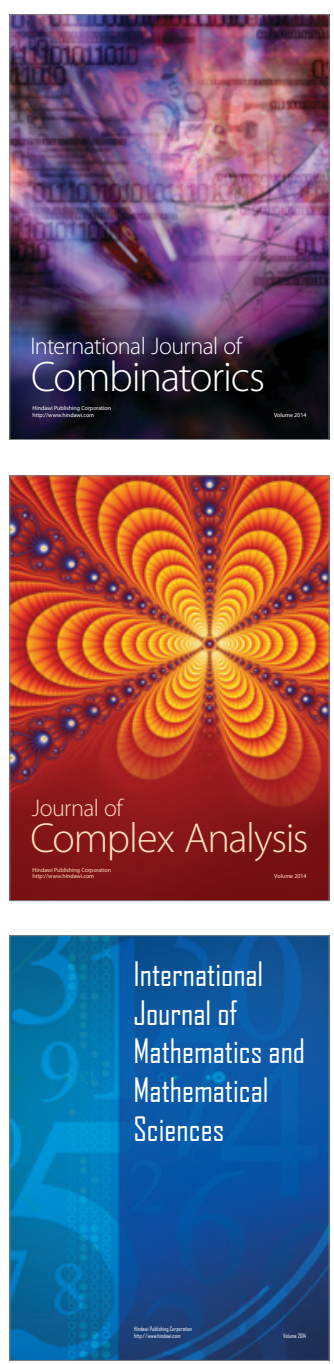
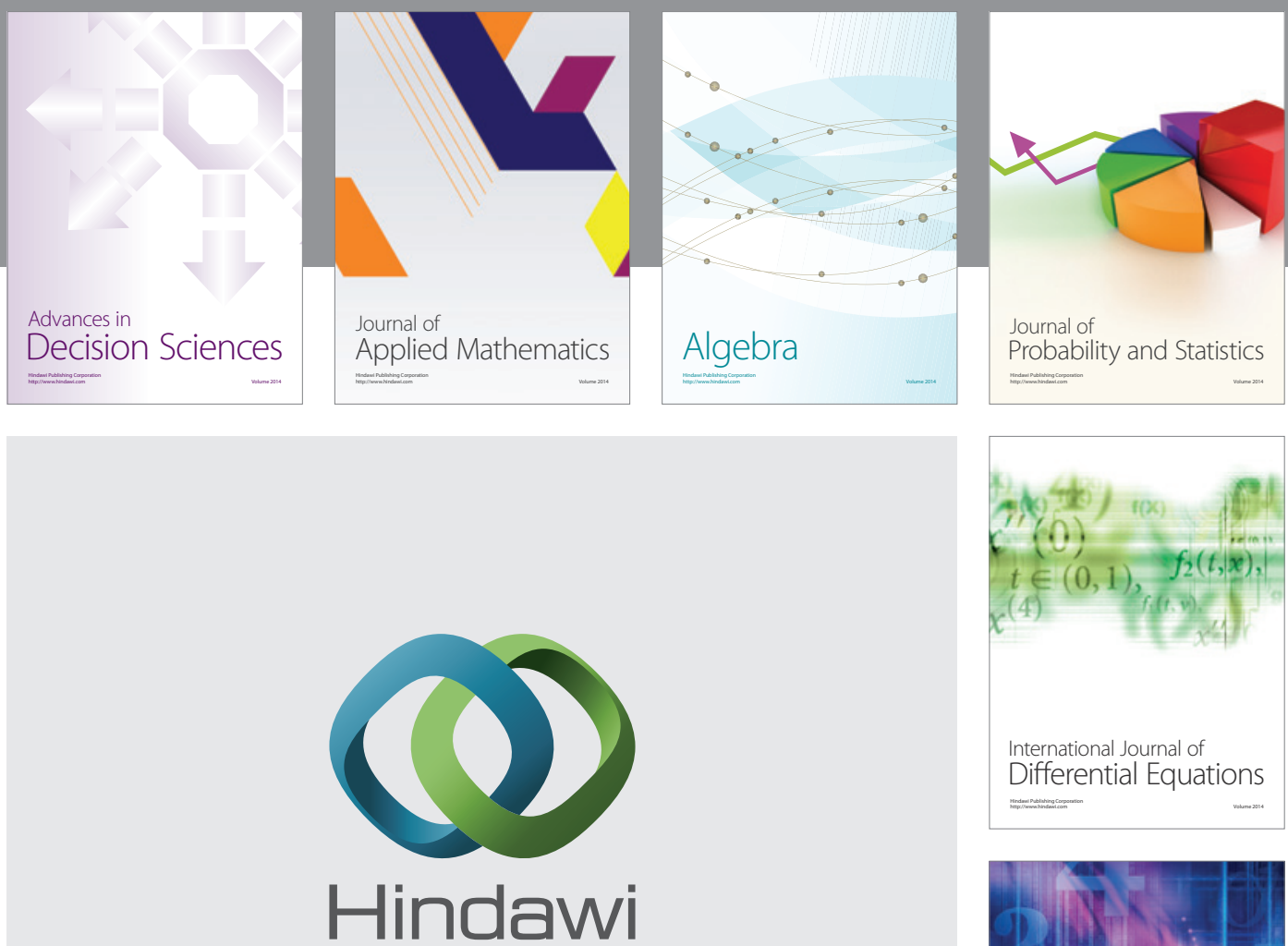

Submit your manuscripts at http://www.hindawi.com
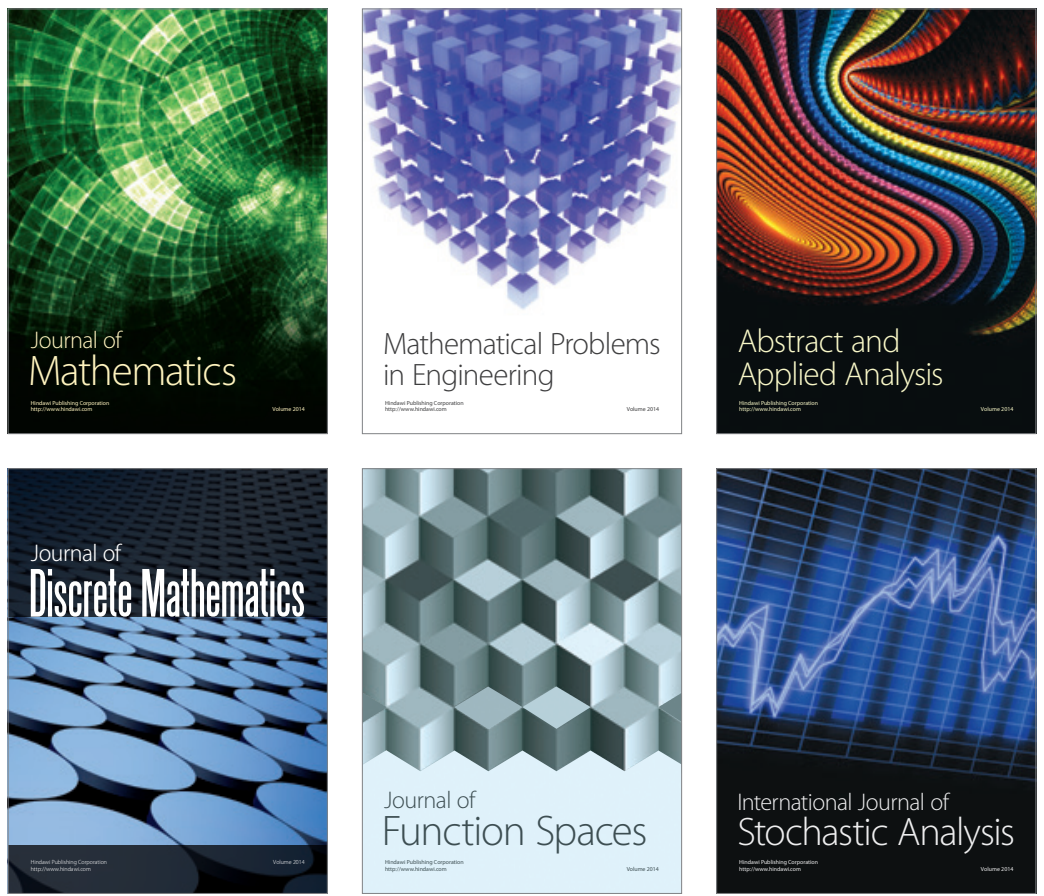

Journal of

Function Spaces

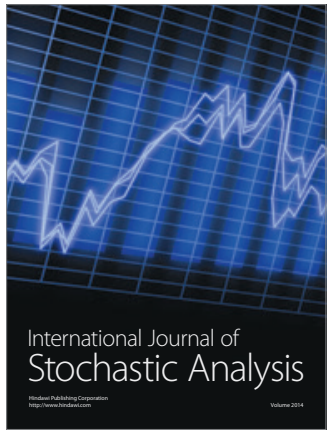

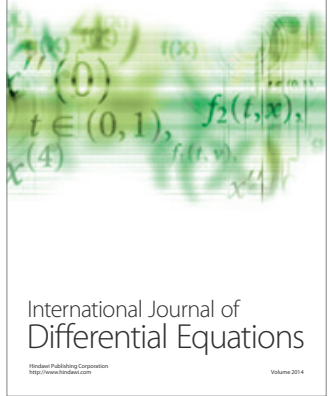
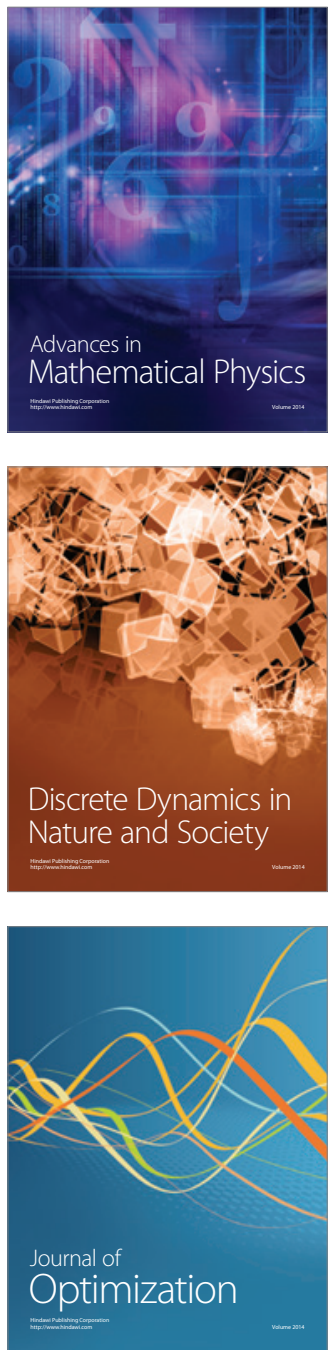